\title{
Inventory ordering policies for mixed sale of products under inspection policy, multiple prepayment, partial trade credit, payments linked to order quantity and full backordering
}

\author{
Ata Allah Taleizadeh ${ }^{1} \cdot$ Sara Tavassoli $^{1} \cdot$ Arijit Bhattacharya $^{2}$ (D)
}

Published online: 21 September 2019

(C) The Author(s) 2019

\begin{abstract}
The situation where serviceable products are sold together with a proportion of deteriorating products to consumers is rarely discussed in the literature. This article proposes an inventory model with disparate inventory ordering policies under a situation where a portion of serviceable products and a portion of deteriorating products are sold together to consumers (i.e. mixed sales). The ordering policies consider a hybrid payment strategy with multiple prepayment and partial trade credit schemes linked to order quantity under situations where no inventory shortage is allowed and inventory shortage is allowed with full backorder. The hybrid payment policy offered by a supplier is introduced into the classical economic ordering quantity model to investigate the optimal inventory cycle and the fraction of demand that is filled from the deteriorating products under inspection policy. Further, a new solution method is proposed that identifies optimal annual total profit with mixed sales assuming no inventory shortage and inventory shortage with full backorder. The impact of an inspection policy is investigated on the optimality of the solution under hybrid payment strategies for the deteriorating products. The validation of the proposed model and its solution method is demonstrated through several numerical examples. The results indicate that the inventory model along with the solution method provide a powerful tool to the retail managers under real-world situations. Results demonstrate that it is essential for the managers to consider inclusion of an inspection policy in the mixed sales of products, as the inspection policy significantly increases the net annual profit.
\end{abstract}

Keywords Ordering policies $\cdot$ Multiple prepayments $\cdot$ Partial trade credit $\cdot$ Inspection policy $\cdot$ Linked to order quantity $\cdot$ Full backordering

Arijit Bhattacharya

A.Bhattacharya@uea.ac.uk; arijit.bhattacharya2005@gmail.com

Extended author information available on the last page of the article 


\section{Introduction}

The classical economic order quantity (EOQ) model has several assumptions that are rarely addressed in the literature. The assumption that the qualities of all products remain perfect is an unrealistic expectation. The model should consider decrease in product quality owing to deterioration that adds to the inventory holding cost (Dobson et al. 2017). Deterioration is a process that decreases usefulness and utility of a product from its original state (Bakker et al. 2012). Research on inventory policies under deterioration usually assumes that deteriorating products are monitored after they are deteriorated. Product samples are inspected to ascertain if they have serviceable quality before storing. The products held in stores gradually deteriorate, and these products are sold together with serviceable products to consumers.

The classical EOQ model assumes that purchasing cost is paid once an order is placed by a retailer. In reality, sometimes a wholesaler prefers the buyer to pay before the date of delivery as a prepayment (i.e. advance payment) to prevent cancellation of the orders and manage the products. Again, some sellers offer their buyers a delayed payment to stimulate their sales.

This research uses the above two realistic incentive schemes, viz. prepayment and trade credit (i.e. delayed payment). Trade credit (Seifert et al. 2013) and prepayments are two widely used incentive schemes in business. Trade credit scheme is used as a motivational policy to increase sales or decrease on hand inventory level to encourage the customers. This scheme motivates the buyers to place larger orders with decreased capital investment.

Prepayment increases sales and promotes the product. Sometimes customers prefer to pay the purchasing cost in advance in several instalments and get the cooperative profit from the manufacturer when the interest earned rate is more than bank's capital rate. To produce a special product, manufacturer may have to pay additional costs for setting up a new process. This requires the manufacturer to get a fraction of production or purchasing cost in advance. This scheme is used to ensure that the buyer will not giving up the order at a loss to the manufacturer.

Inventory model for deteriorating products is a widely researched area (Khan et al., 2011a, b; Olsson 2014; Sarkar et al. 2015; Ghoreishi et al. 2015; Das et al. 2015; Tiwari et al. 2017; Lashgari et al. 2018). The first model (Ghare and Schrader 1963) introduced deterioration of products at a constant deterioration rate into an EOQ model. Goyal and Giri (2001) and Bakker et al. (2012) reported comprehensive reviews of deterioration inventory literature since early 1990s till 2011. Goyal (1985) derived an EOQ model under trade credit. Later, Aggarwal and Jaggi (1995) modified Goyal's model by adding deterioration to the model. The model was further extended by Jamal et al. (1997) considering inventory shortage. Teng (2002) altered Goyal's model (1985) by differentiating the purchasing cost and selling price. Numerous articles in this area have been reported in literature (Teng 2009; Musa and Sani 2012; Guria et al. 2013; Wu et al. 2014; Vandana and Sharma 2016). Examples of trade credit in the models are reported in Min et al. (2010), Chen and Kang (2010), Kreng and Tan (2011), Lee and Rhee (2011), Soni and Patel (2012), Ouyang and Chang (2013), Chen and Teng (2015), Ting (2015). In recent times, Kaya and Polat (2017) proposed a deterministic perishable inventory system with decay. However, literature does not report a model where a portion of deteriorating products and serviceable products are sold together to consumers (Pentico and Drake 2011; Taleizadeh and Noori-Daryan 2015; Tat et al. 2015; Taleizadeh et al. 2013, b, c). 
Khouja and Mehrez (1996) proposed a link to order trade credit, which was extended by Huang (2007) by introducing a partial postponed payment. Ouyang et al. (2009) addressed this issue for deteriorating products under partially delayed payment. Chung (2013) extended the work of Ouyang et al. (2009) by assuming that the interest paid was greater than the interest earned. Chang et al. (2009) addressed a seller-buyer system under link to order trade credit with a descending function of the selling price for demand rate. Maihami et al. (2017) proposed a model under trade credit and partially backlogged shortage for non-instantaneous deteriorating products with price-dependent demand. Mahata et al. (2018) addressed trade credit for deteriorating products considering risk and credit period dependent demand rate. Later, some models in this area were reported by Chung and Liao (2009), Chen et al. (2014), Taleizadeh and Nematollahi (2014) and Jaggi et al. (2017). A comprehensive and up-to-date review of trade credit inventory literature was provided by Kawale and Sanas (2017). More recent literature reports inventory models considering varying deterioration rate with shortages (Prasad and Mukherjee 2016), controllable deterioration rate with shortages (Mishra et al. 2017), prepayment and planned backordering (Taleizadeh et al. 2018), partial prepayment and trade credit (Lashgari et al. 2016), and inventory and credit decisions for deteriorating items (Jaggi et al. 2019). However, these publications do not report any inventory model where a portion of serviceable products and a portion of deteriorating products are sold together to consumers considering multiple prepayments and a partial trade credit linked to order quantity under an inspection policy.

Unlike delayed payment, the impact of prepayment on inventory model has been less investigated in literature. Taleizadeh et al. (2013a) addressed multiple prepayments assuming no inventory shortage with full backlogging and partial backlogging. Taleizadeh (2014a) developed a model under multiple prepayments for deteriorating products with constant deterioration rate. The model was extended for an evaporating product under partial backlogging (Taleizadeh 2014b). Tavakoli and Taleizadeh (2017) proposed an inventory system for a decaying item under full prepayment scheme. Consideration of a combined prepayment and partial trade credit in the inventory model is a realistic assumption. A few articles reported the model with partial prepayment and delayed payments linked to order quantity (Zhang et al. 2014; Zia and Taleizadeh 2015).

Consideration of an inspection policy in the inventory model is scant in the literature. Khan et al. (2011a) used Salameh and Jaber (2000) approach to solve a model consisting of inspection cost and cost of errors due to inappropriate inspection. Tai et al. (2016) presented an inventory model to formulate the process in which deteriorating products were sold together with serviceable products.

Various inventory models on relevant ordering policies reported in the extant literature are mapped and illustrated in Table 1. It is evident from Table 1 that the literature does not report inventory models with an inspection policy, where a portion of serviceable products and a portion of deteriorating products are sold together to consumers considering a hybrid payment scheme having multiple prepayment and partial trade credit linked to the order quantity. Further, the extant literature does not report any inventory model that investigates mixed sales' impact on the annual total profit.

This article addresses the shortcoming of all the previous models (listed in Table 1) in the domain of perishable inventory literature and contributes to the knowledge domain by introducing the following aspects:

- a realistic situation of mixed sale of products is introduced in the inventory model where a portion of deteriorating products and a portion of serviceable products are sold together to consumers, 
Table 1 Identified research gaps on inventory models having disparate ordering policies found from the extant literature

\begin{tabular}{|c|c|c|c|c|c|c|}
\hline \multirow[t]{2}{*}{ Reference } & \multicolumn{2}{|c|}{ Payment schemes } & \multirow{2}{*}{$\begin{array}{l}\text { Linked } \\
\text { to order } \\
\text { quantity }\end{array}$} & \multirow[t]{2}{*}{ Shortage } & \multirow[t]{2}{*}{ Deterioration } & \multirow[t]{2}{*}{ Inspection } \\
\hline & $\begin{array}{l}\text { Advanced } \\
\text { payment }\end{array}$ & Trade credit & & & & \\
\hline Covert and Philip (1973) & & & & No & $\sqrt{ }$ & \\
\hline $\begin{array}{l}\text { Aggarwal and Jaggi } \\
\text { (1995) }\end{array}$ & & $\sqrt{ }$ & & No & $\sqrt{ }$ & \\
\hline Zhang (1996) & $\sqrt{ }$ & & & No & & \\
\hline Jamal et al. (1997) & & $\sqrt{ }$ & & FB & $\sqrt{ }$ & \\
\hline Teng (2002) & & $\sqrt{ }$ & & No & & \\
\hline Huang (2007) & & $\sqrt{ }$ & $\sqrt{ }$ & No & & \\
\hline Chang et al. (2009) & & $\sqrt{ }$ & $\sqrt{ }$ & No & & \\
\hline Maiti et al. (2009) & $\sqrt{ }$ & & & FB & & \\
\hline Teng (2009) & & $\sqrt{ }$ & & No & & \\
\hline Min et al. (2010) & & $\sqrt{ }$ & & No & $\sqrt{ }$ & \\
\hline Skouri et al. (2011) & & $\sqrt{ }$ & & No & $\sqrt{ }$ & \\
\hline Mahata (2012) & & $\sqrt{ }$ & & No & & \\
\hline Soni and Patel (2012) & & $\sqrt{ }$ & & No & & \\
\hline Thangam (2012) & $\sqrt{ }$ & $\sqrt{ }$ & & No & $\sqrt{ }$ & \\
\hline Chung (2013) & & $\sqrt{ }$ & $\sqrt{ }$ & No & $\sqrt{ }$ & \\
\hline Chung et al. (2013) & & $\sqrt{ }$ & $\sqrt{ }$ & No & & \\
\hline Sarkar and Sarkar (2013) & & & & PB & $\sqrt{ }$ & \\
\hline Taleizadeh et al. (2013a) & $\sqrt{ }$ & & & No, FB, PB & & \\
\hline Teng et al. (2013) & & $\sqrt{ }$ & $\sqrt{ }$ & No & & \\
\hline Guria et al. (2013) & & $\sqrt{ }$ & & FB & & \\
\hline Wu et al. (2014) & & $\sqrt{ }$ & & No & $\sqrt{ }$ & \\
\hline Chen et al. (2014) & & $\sqrt{ }$ & $\sqrt{ }$ & No & & \\
\hline Taleizadeh (2014a) & $\sqrt{ }$ & & & FB & $\sqrt{ }$ & \\
\hline Taleizadeh (2014b) & $\sqrt{ }$ & & & PB & $\sqrt{ }$ & \\
\hline Zhang et al. (2014) & $\sqrt{ }$ & $\sqrt{ }$ & & No & & \\
\hline $\begin{array}{l}\text { Zia and Taleizadeh } \\
\quad(2015)\end{array}$ & $\sqrt{ }$ & $\sqrt{ }$ & $\sqrt{ }$ & FB & & \\
\hline Tai et al. (2016) & & & & No, FB & $\sqrt{ }$ & $\sqrt{ }$ \\
\hline This article & $\sqrt{ }$ & $\sqrt{ }$ & $\sqrt{ }$ & No, FB & $\sqrt{ }$ & $\sqrt{ }$ \\
\hline
\end{tabular}

FB Full backordering, $P B$ Partial backordering, No No inventory shortage

- the impact of an inspection policy on the mixed sale of products under a hybrid payment scheme is investigated,

- the hybrid payment policy consisting of multiple prepayment and partial delayed payment is formulated,

- the model is formulated under two situations viz. (i) no inventory shortage and (ii) inventory shortage with full backorder, to analyse the outcomes comprehensively, and 
- a new solution method is provided that examines three decision variables, viz. the replenishment cycle, the fraction of demand which will be filled from the inventory and the inspection time.

The article is organised as follows. Section 2 describes the problem. The mathematical model with disparate inventory ordering policies is proposed in Sect. 3. Section 4 explains the solution method. Section 5 illustrates numerical examples, results and sensitivity analyses of the outcomes, and it further discusses managerial implication of the results. Section 6 concludes the article with an implication to future research.

\section{Problem description}

The notations used in formulating the inventory models are illustrated in Table 6 ("Appendix A"). Situations arise when deteriorating products and serviceable products are sold together to the consumers (Fig. 1). When the defective products are sold to the consumers, the sales volume decreases because of return of the products. Further, the payment strategy comprises a hybrid payment scheme in which the wholesaler desires his buyer to prepay purchasing cost as multiple prepayments in equal instalments before the orders are delivered, if the order quantity is less than a specific threshold value, $W$ (i.e., Case 1: $T \leq T_{w}$ ). Alternatively, the buyer is offered to prepay $\beta$ percent of the purchasing cost and pay $(1-\beta)$ percent of the cost as partial trade credit (i.e. delayed payment) (i.e., Case 2: $T>T_{w}$ ). Case 2 is divided based on the values of $T_{0}$ into three possible sub-cases, viz. Case 2.1: $T_{0} \leq M \leq F T$, Case 2.2: $M \leq T_{0}$ and Case 2.3: $M \geq F T$. Case 2.1 defines the situation where the remaining amount of the purchasing cost is settled between the times that $\beta Q$ units and $Q$ units are depleted to zero as delayed payment. Case 2.2 defines the situation where the remaining amount of the purchasing cost is settled before the time that $\beta Q$ units are depleted to zero as trade credit. Case 2.3 defines the situation where the remaining purchasing cost is settled after the inventory on-hand reaches to zero. It is assumed that the interest paid in stocks is greater than the interest earned in investment.

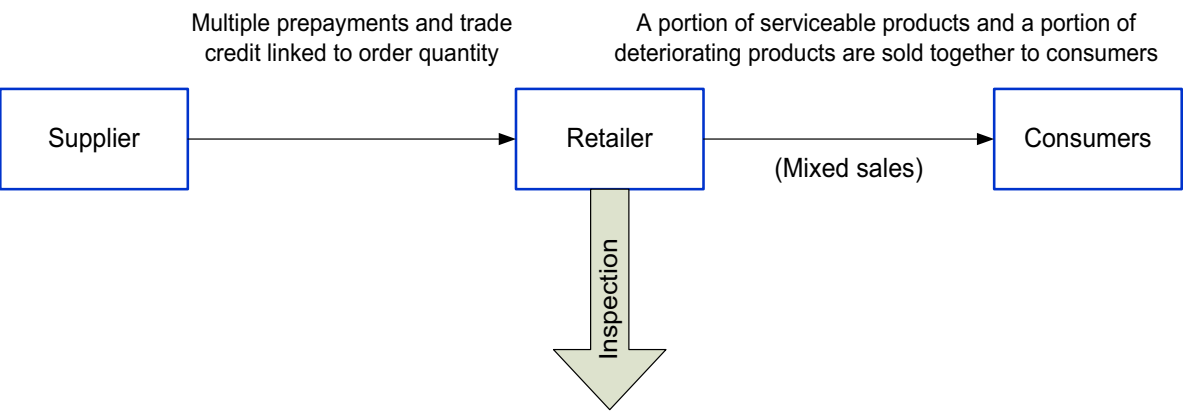

The products which are deteriorated since beginning are screened out

Fig. 1 A schematic illustration of the problem 


\section{The mathematical model}

The inventory model with partial prepayment and trade credit (i.e. delayed payment) schemes linked to order quantity under inspection policy for mixed sale of products are formulated under two situations, viz. (1) without inventory shortage and (2) with inventory shortage and full backorder. To formulate the mathematical model, the following assumptions are made:

1. A supply chain with a single deteriorating product and a single serviceable product is considered,

2. A linked to order trade credit is assumed for the upstream side of the supply chain,

3. A prepayment in the downstream of the supply chain is considered,

4. The prepayments are in multiple equal sizes,

5. A shortage is permitted,

6. The shortage products are fully backordered,

7. The deterioration and demand rates are assumed to be deterministic and constant, and

8. All inputs are deterministic.

The following Sects. 3.1 and 3.2 elucidate the model with the disparate inventory ordering policies.

\subsection{The model without inventory shortage}

Inventory level decreases with demand rate $(\lambda>0)$ and deterioration rate $(\theta>0)$ of an inventory system. Let $I(t)$ and $J(t)$ are levels of serviceable and deteriorating products at any time $t(0 \leq t \leq T)$ in the inventory system respectively. $I(t)$ and $J(t)$ are derived as follows (Tai et al. 2016):

$$
\left\{\begin{array}{l}
I(t)=(Q-\lambda t) \times e^{-\theta t} \\
J(t)=(Q-\lambda t) \times\left(1-e^{-\theta t}\right)
\end{array} \rightarrow I(t)+J(t)=(Q-\lambda t)\right.
$$

The serviceable products which are sold to consumers during time $T$ are obtained as follows (Tai et al. 2016):

$$
\lambda \int_{0}^{T} \frac{I(t)}{I(t)+J(t)} d t=\lambda \int_{0}^{T} e^{-\theta t} d t=\frac{\lambda}{\theta}\left(1-e^{-\theta T}\right)
$$

A hybrid payment scheme is considered with an assumption that if the order quantity is lower than a specific threshold value (i.e. $W>Q$ ), full purchasing cost must be prepaid beforehand. Alternatively, when $Q>W$ or $T>T_{w}$, a fraction of the purchasing cost must be prepaid before delivery of the order. For the rest amount of the purchasing cost a partial trade credit is offered. It is to be noted that, by substituting the Taylor series expansion $\left(e_{\theta T^{2}}^{x} \approx 1+x+\frac{x^{2}}{2}\right)$ into Eq. (2), the serviceable products become equivalent to $\lambda\left(T_{i}-\frac{\theta T_{i}^{2}}{2}\right)$ (where $i$ refers to Cases 1, 2.1, 2.2 and 2.3). 


\subsubsection{Inventory scenarios}

Two scenarios of inventory can arise, viz. (1) $T<T_{w}$ and (2) $T_{w} \leq T$. Some components of the total profit function per year are identical in these two possible cases. The identical components of objective functions are the holding cost, fixed ordering cost, purchasing cost, and sales revenue which are equal to $\frac{C_{h} \lambda T}{2}, \frac{A}{T}, C_{p} \lambda$, and $P\left[\frac{\lambda}{\theta} \frac{\left(1-e^{-\theta T}\right)}{T}\right]$ respectively. Three feasible situations arise based on the values of $T$ and $T_{w}$. Non-identical terms of the inventory system in each of these cases are described below.

Case $1 T<T_{w}$

As illustrated in Fig. 2, full purchasing cost is paid as a prepayment in $n$ equal instalments before receiving an order. Further, no delayed payment is offered. Therefore, no annual interest is earned. The cyclic capital costs of prepayments are equal to:

$$
\begin{aligned}
I C_{1}= & \left(i_{k} \frac{C_{p} \lambda T}{n} \times n \times \frac{L}{n}\right)+\left(i_{k} \frac{C_{p} \lambda T}{n} \times(n-1) \times \frac{L}{n}\right)+\cdots+\left(i_{k} \frac{C_{p} \lambda T}{n} \times 1 \times \frac{L}{n}\right) \\
& =i_{k} C_{p} \lambda T \frac{(n+1)}{2 n} L
\end{aligned}
$$

Therefore, the annual total profit per unit, $\operatorname{ATP}_{1}(T)$, is:

$$
A T P_{1}(T)=P\left[\frac{\lambda}{\theta} \frac{\left(1-e^{-\theta T}\right)}{T}\right]-\left[\frac{A}{T}+\frac{C_{h} \lambda T}{2}+C_{p} \lambda+i_{k} C_{p} \lambda \frac{(n+1)}{2 n} L\right]
$$

Case $2 T \geq T_{w}$

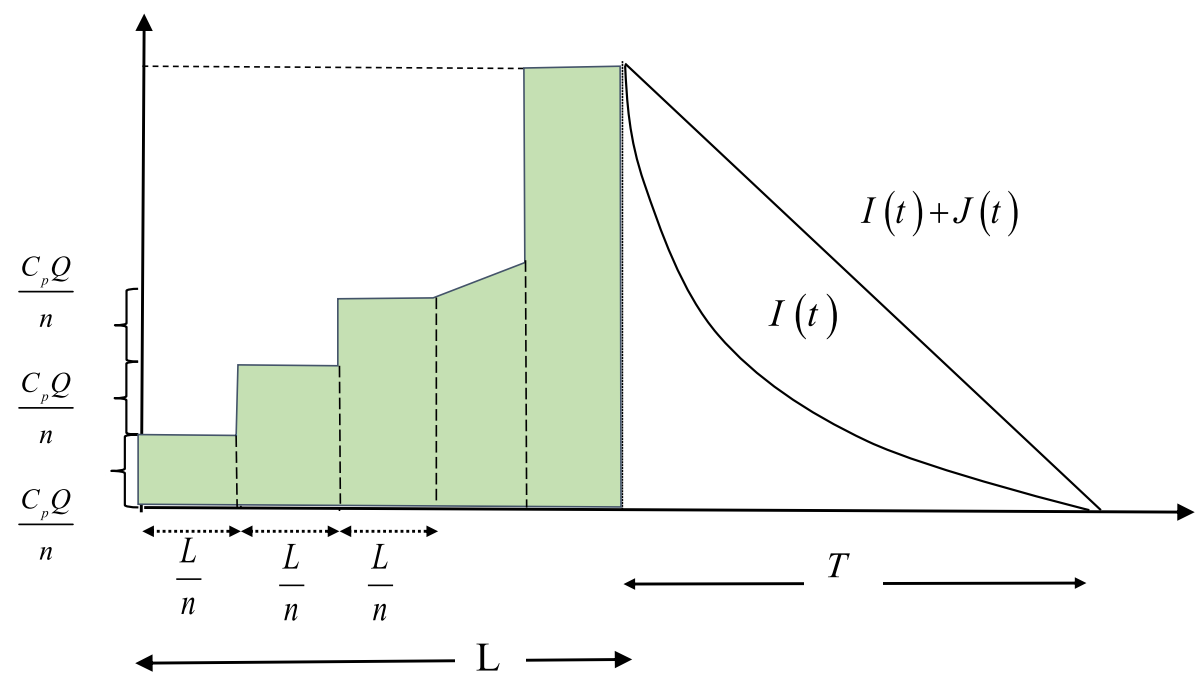

Fig. 2 The interest earned and paid for the model without inventory shortage (Case 1) 
In this scenario, $\beta$ percent of the purchasing cost is paid as a prepayment in $n$ equal instalments before receiving an order. The rest is paid as a delayed payment. Based on the values of $T, T_{0}=\beta T$ and $M$, the following three possible sub-cases are identified:

Case 2.1 $\beta T \leq M \leq T \rightarrow M \leq T \leq \frac{M}{\beta}$

This means that the remaining amount of the purchasing cost is settled between time $T_{0}$ and $T$. A combination of this possibility and $T_{w}<T$ give rise to the following two sub-cases:

Case 2.1.1 $T_{w}<M \leq T \leq \frac{M}{\beta}$, and

Case 2.1.2 $M<T_{w} \leq T<\frac{M}{\beta}$

As illustrated in Fig. 3, both of these sub-cases have same cost of interest charged $\left(\mathrm{IC}_{21}\right)$, interest earning $\left(\mathrm{IE}_{21}\right)$ and annual total profit $\left[\mathrm{ATP}_{21}(\mathrm{~T})\right]$, and these are depicted in Eqs. (5), (6) and (7) respectively.

$$
\begin{gathered}
I C_{2.1}=\beta i_{k} C_{p} \lambda \frac{(n+1)}{2 n} L+i_{k} C_{p} \lambda \frac{(T-M)^{2}}{2 T} \\
I E_{2.1}=(1-\beta) i_{e} P \frac{\lambda}{\theta} \frac{\left(1-e^{-\theta M}\right)}{T} \\
A T P_{2.1}(T)=P\left[\frac{\lambda}{\theta} \frac{\left(1-e^{-\theta T}\right)}{T}\right]+\left[(1-\beta) i_{e} P \frac{\lambda}{\theta} \frac{\left(1-e^{-\theta M}\right)}{T}\right] \\
-\left[\frac{A}{T}+C_{p} \lambda+C_{h} \frac{\lambda T}{2}+\beta i_{k} C_{p} \lambda \frac{(n+1)}{2 n} L+i_{k} C_{p} \lambda \frac{(T-M)^{2}}{2 T}\right]
\end{gathered}
$$

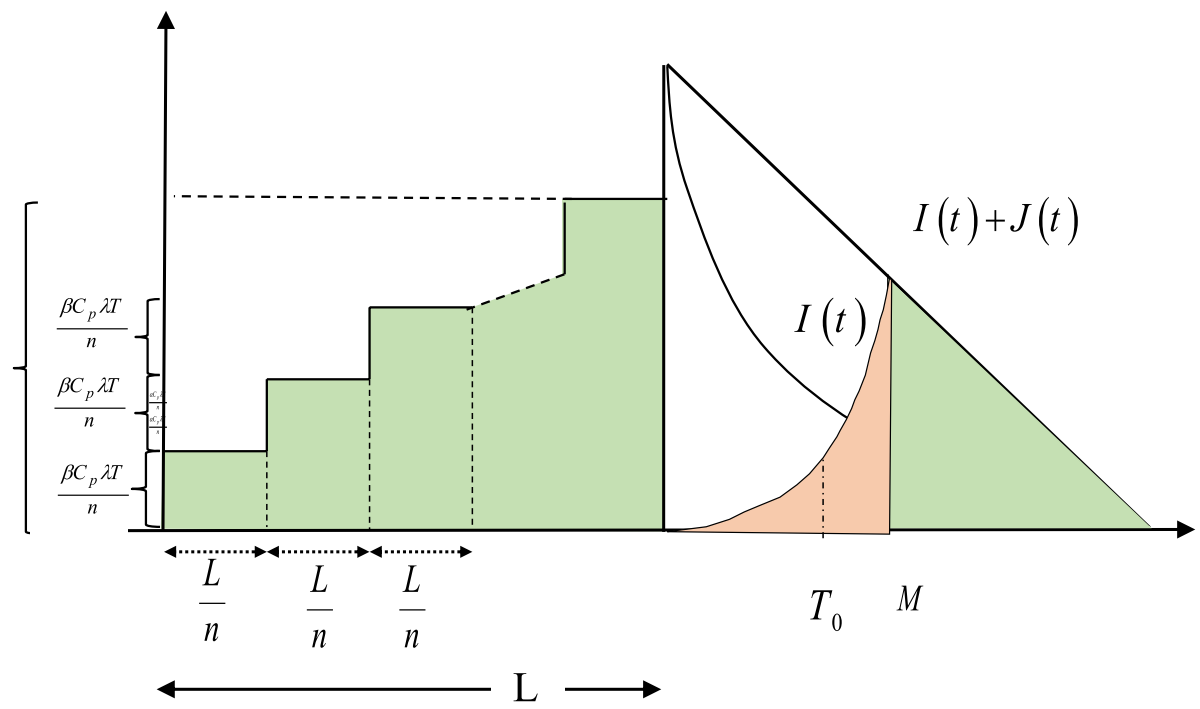

Fig. 3 The interest earned and paid for the model without inventory shortage (Case 2.1) 
Case 2.2 $\beta T \geq M \rightarrow \frac{M}{\beta} \leq T$

The remaining portion of the purchasing cost is settled before time $T_{0}$. A combination of this possibility and $T_{w}<T$ give rise to the following two situations:

Case 2.2.1 $T_{w}<\frac{M}{\beta} \leq T$, and

Case 2.2.2 $\frac{M}{\beta}<T_{w} \leq T$

These two sub-cases have the same cost of interest charged $\left(\mathrm{IC}_{22}\right)$, interest earning $\left(\mathrm{IE}_{22}\right)$ and total profit $\left[\mathrm{ATP}_{22}(\mathrm{~T})\right]$ as illustrated in Fig. 4, and these are depicted in Eqs. (8), (9) and (10) respectively.

$$
\begin{gathered}
I C_{2.2}=\beta i_{k} C_{p} \lambda \frac{(n+1)}{2 n} L \\
I E_{2.2}=(1-\beta) i_{e} P \frac{\lambda}{\theta} \frac{\left(1-e^{-\theta M}\right)}{T} \\
A T P_{2.2}(T)=P\left[\frac{\lambda}{\theta} \frac{\left(1-e^{-\theta T}\right)}{T}\right]+\left[(1-\beta) i_{e} P \frac{\lambda}{\theta} \frac{\left(1-e^{-\theta M}\right)}{T}\right] \\
-\left[\frac{A}{T}+C_{h} \frac{\lambda T}{2}+C_{p} \lambda+\beta i_{k} C_{p} \lambda T \frac{(n+1)}{2 n} L\right]
\end{gathered}
$$

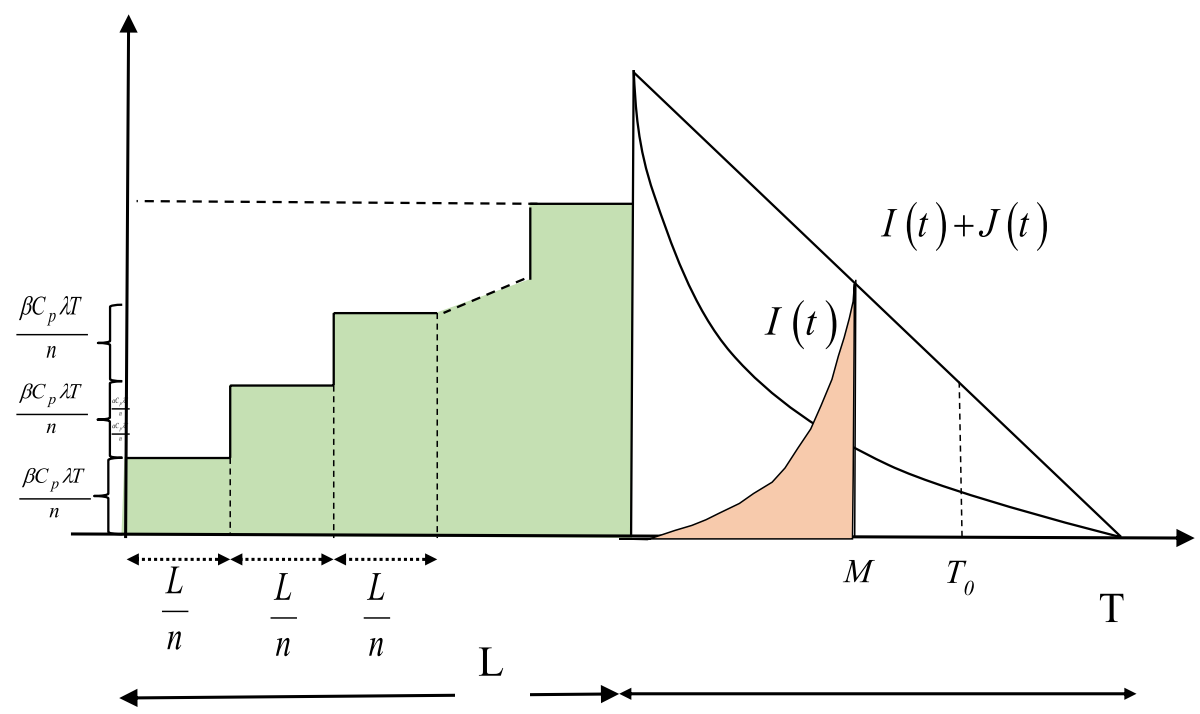

Fig. 4 The interest earned and paid for the model without inventory shortage (Case 2.2) 
Case 2.3 $M \geq T$

The remaining portion of the purchasing cost is settled after a replenishment cycle ends in this sub-case. A combination of this possibility and $T_{w}<T$ give rise to the situation of Case 2.3.1:

Case 2.3.1 $T_{w} \leq T<M$

For this situation, the interest charged $\left(\mathrm{IC}_{23}\right)$, interest earning $\left(\mathrm{IE}_{23}\right)$ and annual total profit $\left[\mathrm{ATP}_{23}(\mathrm{~T})\right]$ are depicted in Eqs. (11), (12) and (13) respectively (Fig. 5).

$$
\begin{gathered}
I C_{2.3}=\beta i_{k} C_{p} \lambda \frac{(n+1)}{2 n} L \\
I E_{2.3}=i_{e} \frac{P \lambda}{\theta} \frac{\left(1-e^{-\theta T}\right)}{T}+(1-\beta) i_{e} P \lambda F(M-T) \\
A T P_{2.3}(T)=P\left[\frac{\lambda}{\theta} \frac{\left(1-e^{-\theta T}\right)}{T}\right]+\left[(1-\beta) i_{e} \frac{P \lambda}{\theta} \frac{\left(1-e^{-\theta T}\right)}{T}+(1-\beta) i_{e} P \lambda(M-T)\right] \\
-\left[\frac{A}{T}+C_{h} \frac{\lambda T}{2}+C_{p} \lambda+\beta i_{k} C_{p} \lambda \frac{(n+1)}{2 n} L\right]
\end{gathered}
$$

\subsection{The model with backordering (i.e. with inventory shortage)}

Considering the situations stated in the earlier assumptions along with shortage of the products, let us assume that the inventory level reaches zero and the shortage products are completely backordered. In this model with backordering, some elements of the total profit function per year are identical to that of the model without inventory shortage.

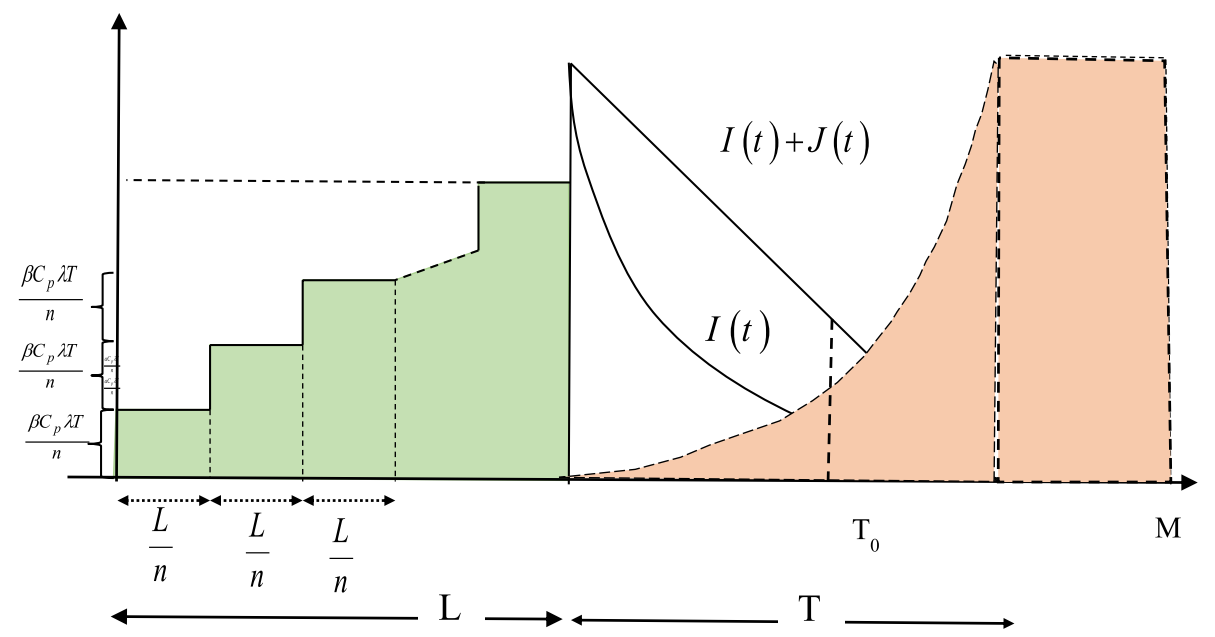

Fig. 5 The interest earned and paid for the model without inventory shortage (Case 2.3) 
The identical components of the objective function are fixed ordering cost $\left(\frac{A}{T}\right)$, holding $\operatorname{cost}\left(\frac{C_{h} \lambda F^{2} T}{2 F T}\right)$, purchasing cost $\left(C_{p} \lambda\right)$, backordering cost $\left(C_{b} \frac{\lambda(1-F)^{2} T}{2}\right)$ and sales revenue $P\left[\frac{\lambda}{\theta} \frac{\left(1-e^{-\partial F T}\right)}{T}+\lambda(1-F)\right]$. Based on the values of $T_{0}\left(\right.$ obtained as $\left.T_{0}=\beta F T\right), T_{w}$ and $T$, three possible cases are identified. The components that differ between the cases are computed in the following paragraphs.

Case $1 T<T_{w}$

In this case, as illustrated in Fig. 6, no interest is earned and the cyclic capital costs of prepayment are computed similar to the model without inventory shortage. The cyclic capital costs are given by:

$$
C C_{1}=i_{k} C_{p} \lambda T \frac{(n+1)}{2 n} L
$$

Therefore, the annual total profit per unit, $\operatorname{ATP}_{1}(T, F)$, is:

$$
\begin{aligned}
A T P_{1}(T, F)= & P\left[\frac{\lambda}{\theta} \frac{\left(1-e^{-\theta F T}\right)}{T}+\lambda(1-F)\right] \\
& -\left[\frac{A}{T}+C_{h} \frac{\lambda F^{2} T}{2}+C_{p} \lambda+C_{b} \frac{\lambda(1-F)^{2} T}{2}+i_{k} C_{p} \lambda \frac{(n+1)}{2 n} L\right]
\end{aligned}
$$

Case $2 T \geq T_{w}$

The payment strategy used in this case is: $\beta$ percent of the purchasing cost is paid as a prepayment in $n$ equal instalments before receiving an order, and the rest is paid as a delayed payment. Based on the values of $T_{0}=\beta F T, M, F$ and $T$, the following three sub-cases evolve:

Case 2.1 $\beta F T \leq M \leq F T \rightarrow \frac{M}{F} \leq T \leq \frac{M}{\beta F}$

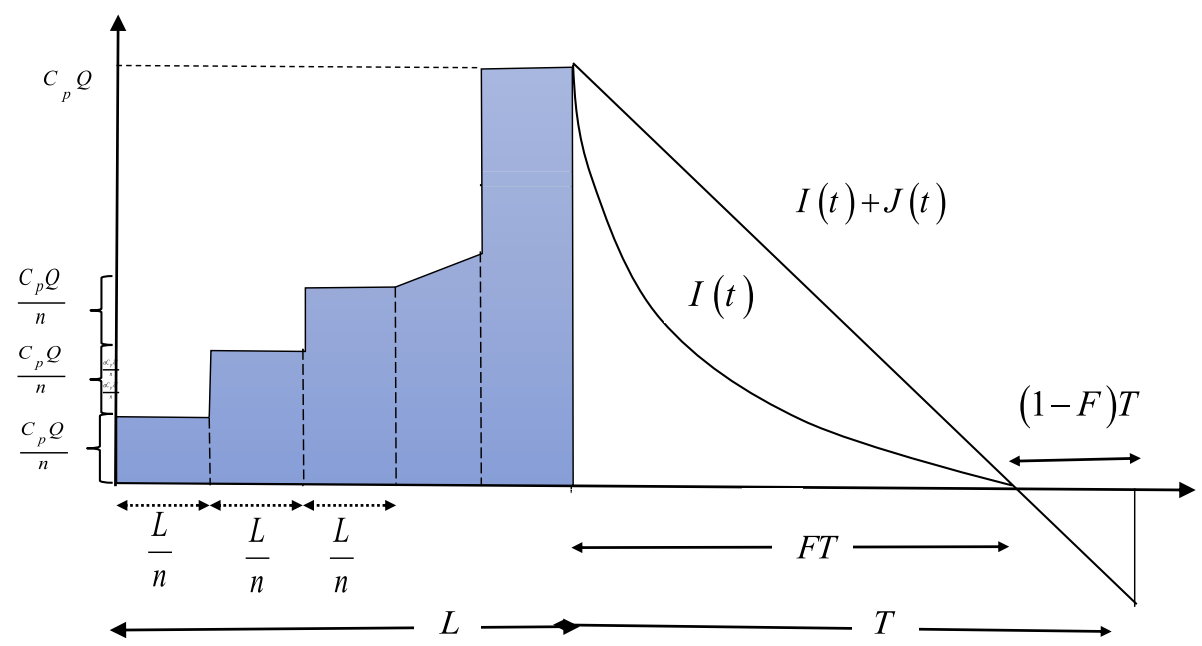

Fig. 6 The interest earned and paid for the model with inventory shortage (Case 1) 
In this sub-case, the remaining portion of the purchasing cost is settled between the time $T_{0}$ and $T$. A combination of the mentioned condition and $T_{w}<T$, give rise to the following two situations:

Case 2.1.1 $T_{w}<\frac{M}{F} \leq T<\frac{M}{\beta F}$, and

Case 2.1.2 $\frac{M}{F}<T_{w} \leq T<\frac{\beta F}{\beta F}$

The sub-cases have the same cost of interest charged $\left(\mathrm{IC}_{21}\right)$, interest earning $\left(\mathrm{IE}_{21}\right)$ and annual total profit $\left[\operatorname{ATP}_{21}(T, F)\right]$ as depicted in Eqs. (16), (17) and (18) respectively. The situations have been elucidated in Fig. 7.

$$
\begin{gathered}
I C_{2.1}=\beta i_{k} C_{p} \lambda \frac{(n+1)}{2 n} L+i_{k} C_{p} \lambda \frac{(F T-M)^{2}}{2 T} \\
I E_{2.1}=(1-\beta) i_{e} P \frac{\lambda}{\theta} \frac{\left(1-e^{-\theta M}\right)}{T}+(1-\beta) i_{e} P \lambda M(1-F) \\
\operatorname{ATP}_{2.1}(T, F)=P\left[\frac{\lambda}{\theta} \frac{\left(1-e^{-\theta F T}\right)}{T}+\lambda(1-F)\right]+\left[(1-\beta) i_{e} P \frac{\lambda}{\theta} \frac{\left(1-e^{-\theta M}\right)}{T}+(1-\beta) i_{e} P \lambda M(1-F)\right] \\
-\left[\frac{A}{T}+C_{h} \frac{\lambda F^{2} T}{2}+C_{b} \frac{\lambda(1-F)^{2} T}{2}+C_{p} \lambda+\beta i_{k} C_{p} \lambda \frac{(n+1)}{2 n} L+i_{k} C_{p} \lambda \frac{(F T-M)^{2}}{2 T}\right]
\end{gathered}
$$

Case 2.2 $M \leq \beta F T \rightarrow \frac{M}{\beta F} \leq T$

In this sub-case, the remaining amount of the purchasing cost is settled before time $T_{0}$. A combination of the stated condition and $T_{w}<T$ give rise to the following two possible situations:

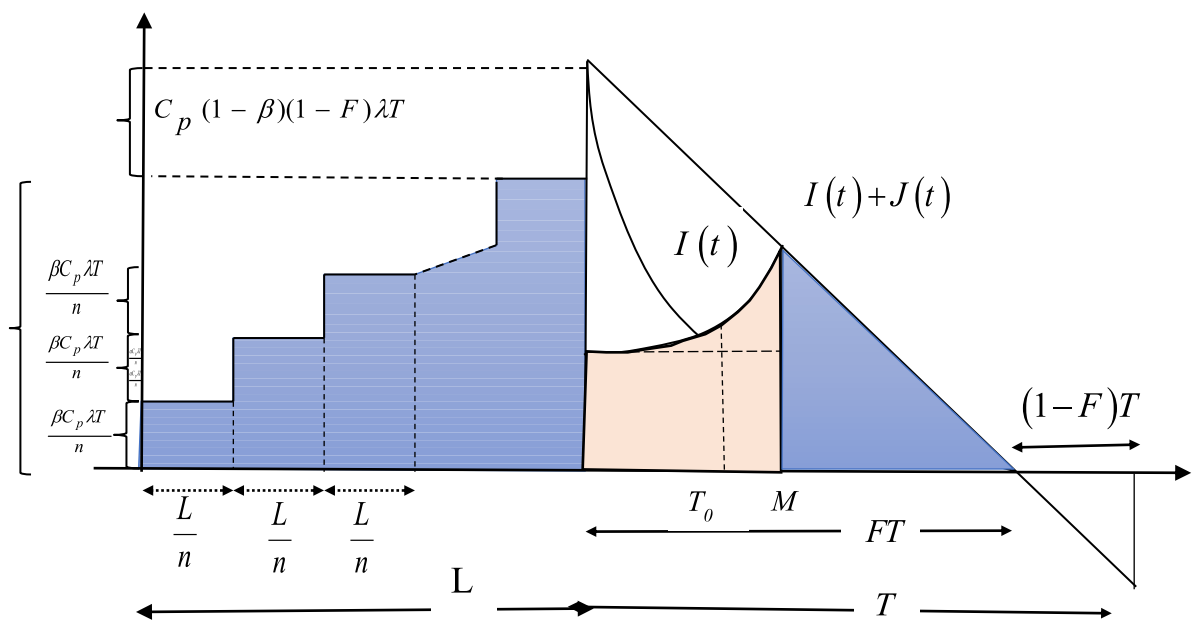

Fig. 7 The interest earned and paid for the model with inventory shortage (Case 2.1) 
Case 2.2.1: $T_{w}<\frac{M}{\beta F} \leq T$, 2.2.2: $\frac{M}{\beta F}<T_{w} \leq T$.

These sub-cases have the same cost of interest charged $\left(\mathrm{IC}_{22}\right)$, interest earning $\left(\mathrm{IE}_{22}\right)$ and annual total profit $\left[\operatorname{ATP}_{22}(T, F)\right]$ as depicted in Eqs. (19), (20) and (21) respectively. This has been elucidated in Fig. 8.

$$
\begin{gathered}
I C_{2.2}=\beta i_{k} C_{p} \lambda \frac{(n+1)}{2 n} L-(1-\beta) i_{k} C_{p} \lambda F M \\
I E_{2.2}=(1-\beta) i_{e} P \frac{\lambda}{\theta} \frac{\left(1-e^{-\theta M}\right)}{T}+(1-\beta) i_{e} P \lambda M(1-F) \\
A T P_{2.2}(T, F)=P\left[\frac{\lambda}{\theta} \frac{\left(1-e^{-\theta F T}\right)}{T}+\lambda(1-F)\right]+\left[(1-\beta) i_{e} P \frac{\lambda}{\theta} \frac{\left(1-e^{-\theta M}\right)}{T}+(1-\beta) i_{e} P \lambda M(1-F)\right] \\
-\left[\frac{A}{T}+C_{h} \frac{\lambda F^{2} T}{2}+C_{b} \frac{\lambda(1-F)^{2} T}{2}+C_{p} \lambda+\beta i_{k} C_{p} \lambda T \frac{(n+1)}{2 n} L-(1-\beta) i_{k} C_{p} \lambda F M\right]
\end{gathered}
$$

Case 2.3 $F T \leq M \rightarrow T \leq \frac{M}{F}$

In this sub-case, the remaining purchasing cost is settled after the inventory on-hand reaches zero. A combination of $T_{w}<T$ and the stated condition results in the following possible situation:

Case 2.3.1 $T_{w} \leq T<\frac{M}{F}$

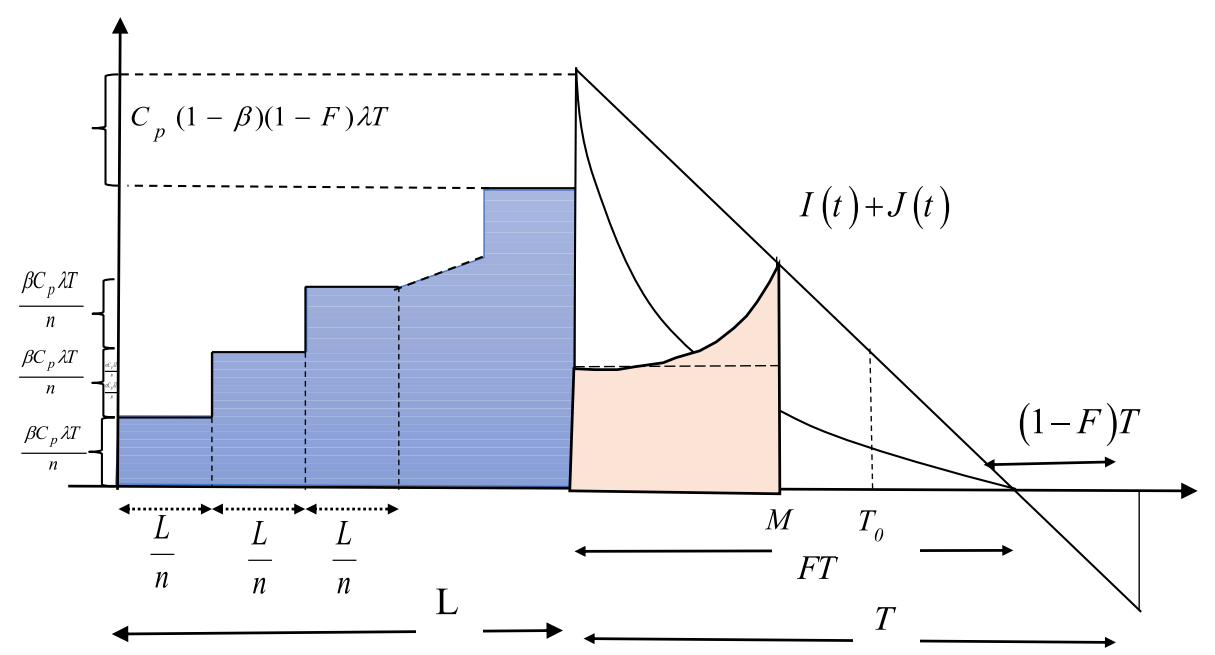

Fig. 8 The interest earned and paid for the model with inventory shortage (Case 2.2) 
The cost of interest charged $\left(\mathrm{IC}_{23}\right)$, interest earning $\left(\mathrm{IE}_{23}\right)$ and annual total profit $\left[\mathrm{ATP}_{23}(T\right.$, $F)]$ are obtained as depicted in Eqs. (22), (23) and (24) respectively. These are elucidated in Fig. 9.

$$
\begin{gathered}
I C_{2.3}=\beta i_{k} C_{p} \lambda \frac{(n+1)}{2 n} L \\
I E_{2.3}=(1-\beta)\left[i_{e} \frac{P \lambda}{\theta} \frac{\left(1-e^{-\theta F T}\right)}{T}+i_{e} P \lambda M(1-F)+i_{e} P \lambda F(M-F T)\right] \\
A T P_{2.3}(T, F)=P\left[\frac{\lambda}{\theta} \frac{\left(1-e^{-\theta F T}\right)}{T}+\lambda(1-F)\right] \\
+\left[(1-\beta) \times\left[i_{e} \frac{P \lambda}{\theta} \frac{\left(1-e^{-\theta F T}\right)}{T}+i_{e} P \lambda M(1-F)+i_{e} P \lambda F(M-F T)\right]\right] \\
-\left[\frac{A}{T}+C_{h} \frac{\lambda F^{2} T}{2}+C_{b} \frac{\lambda(1-F)^{2} T}{2}+C_{p} \lambda+\beta i_{k} C_{p} \lambda \frac{(n+1)}{2 n} L\right]
\end{gathered}
$$

\section{The solution method}

This section elucidates a closed form solution for the optimal variables of each case of the two formulated models in order to maximise the annual total profit. Section 4.3 delineates the integration of the inspection policy with the proposed model, which reduces the chance of delivering deteriorating products to the customers maximising the annual total profit.

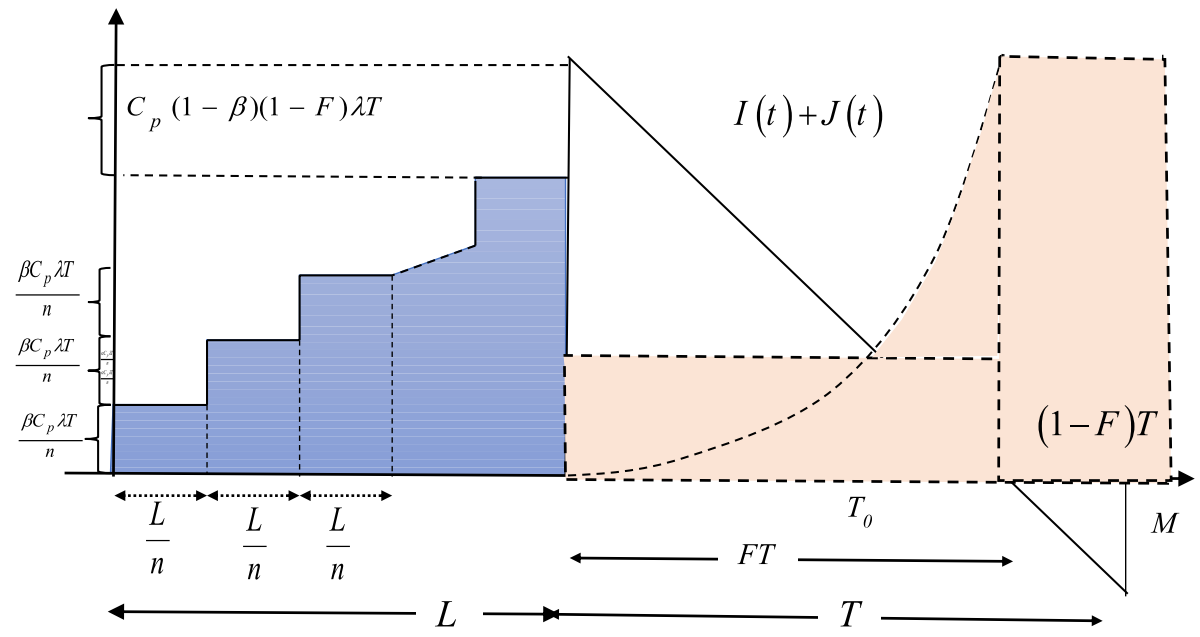

Fig. 9 The interest earned and paid for the model with inventory shortage (Case 2.3) 


\subsection{The model without inventory shortage}

In this sub-section, the optimal solution $T$ is determined in each case so that the annual total profit of the model without inventory shortage is optimised.

Case 1: We apply the Taylor series expansion for the exponential term (i.e. $e^{x} \approx 1+x+\frac{x^{2}}{2}$ ) for small value of the deterioration rate to obtain an approximation in a closed form. After substituting the term in Eq. (4) and simplifying the expression we obtain:

$$
A T P_{1}(T)=\left[P-C_{p}-i_{k} C_{p} \frac{(n+1)}{2 n} L\right] \lambda-\underbrace{\left[T\left(P \lambda \frac{\theta}{2}+C_{h} \frac{\lambda}{2}\right)+\frac{A}{T}\right]}_{A T C_{1}(T)}
$$

Maximising $A T P_{1}(T)$ is equivalent to minimising $A T C_{1}(T)$, where

$$
A T C_{1}(T)=T \varphi_{1}+\frac{\varphi_{2}}{T}
$$

and $\varphi_{1}=P \frac{\theta \lambda}{2}+C_{h} \frac{\lambda}{2}>0$, and $\varphi_{2}=A>0$.

Therefore, by setting the first partial derivative of $A T C_{1}(T)$ with reference to $T$ equal to 0 yields to:

$$
T_{(1)}=\sqrt{\frac{\varphi_{2}}{\varphi_{1}}}
$$

The value provided in Eq. (27) is the unique global optimum solution of the inventory problem. This is demonstrated in "Appendix B" using the approach of Pentico et al. (2009).

Case 2.1: By substituting $e^{x} \approx 1+x+\frac{x^{2}}{2}$ in Eq. (10) and simplifying the expression we obtain:

$$
\begin{aligned}
\operatorname{ATP}_{2.1}(T)= & {\left[P-C_{p}-\beta i_{k} C_{p} \frac{(n+1)}{2 n} L+i_{k} C_{p} M\right] \lambda } \\
& -\underbrace{\left[T\left(P \frac{\theta \lambda}{2}+C_{h} \frac{\lambda}{2}+\frac{i_{k} C_{p} \lambda}{2}\right)+\frac{1}{T}\left(A+(1-\beta) i_{e} P \lambda\left(\frac{\theta M^{2}}{2}-M\right)+\frac{i_{k} C_{p} \lambda M^{2}}{2}\right)\right]}_{A T C_{2.1}(T)}
\end{aligned}
$$

Maximising $A T P_{2.1}(T)$ is equivalent to minimising $A T C_{2.1}(T)$, where:

$$
A T C_{2.1}(T)=\frac{1}{T} \phi_{2}+T \phi_{1}
$$

and $\phi_{1}=P \frac{\theta \lambda}{2}+C_{h} \frac{\lambda}{2}+\frac{i_{k} C_{p} \lambda}{2}>0$, and

$$
\phi_{2}=A+\frac{i_{k} C_{p} \lambda M^{2}}{2}+(1-\beta) i_{e} P \lambda\left(\frac{\theta M^{2}}{2}-M\right)>0
$$

Therefore, by setting the first partial derivative of $A T C_{2.1}(T)$ with reference to $T$ equal to 0 yields to: 


$$
T_{(2.1)}=\sqrt{\frac{\phi_{2}}{\phi_{1}}}
$$

The value obtained in Eq. (30) is the unique global optimum solution of the inventory problem. This is demonstrated in "Appendix B" using the approach of Pentico et al. (2009).

Case 2.2: By using $e^{x} \approx 1+x+\frac{x^{2}}{2}$ term, substituting it into Eq. (13) and simplifying the expression we obtain:

$$
\begin{aligned}
A T P_{2.2}(T)= & {\left[P-C_{p}-\beta i_{k} C_{p} \lambda \frac{(n+1)}{2 n} L\right] } \\
& -\underbrace{\left[T\left(P \frac{\lambda \theta}{2}+C_{h} \frac{\lambda}{2}\right)+\frac{1}{T}\left(A+(1-\beta) i_{e} P \lambda\left(M-\frac{\theta M^{2}}{2}\right)\right)\right]}_{A T C_{2.2}(T)}
\end{aligned}
$$

Maximising $A T P_{2.2}(T)$ is equivalent to minimising $A T C_{2.2}(T)$. For notational convenience we consider:

$$
\operatorname{ATC}_{2.2}(T)=T v_{1}+\frac{1}{T} v_{2}
$$

where $v_{1}=P \frac{\lambda \theta}{2}+C_{h} \frac{\lambda}{2}>0$, and $v_{2}=A+i_{e}(1-\beta) P \lambda\left(\frac{\theta M^{2}}{2}-M\right)>0$

Therefore, by setting the first partial derivative of $A T C_{2.1}(T)$ with reference to $T$ equal to 0 yields to:

$$
T_{(2.2)}=\sqrt{\frac{v_{2}}{v_{1}}}
$$

Again, the value provided in Eq. (33) is the unique global optimum solution of the inventory problem. This has been demonstrated in "Appendix B" using the approach of Pentico et al. (2009).

Case 2.3: By using $e^{x} \approx 1+x+\frac{x^{2}}{2}$, substituting it into Eq. (13), and simplifying the expression we obtain:

$$
\begin{aligned}
\operatorname{ATP}_{2.3}(T)= & {\left[P-C_{p}-\beta i_{k} C_{p} \frac{(n+1)}{2 n} L+(1-\beta) i_{e} P M+(1-\beta) i_{e} P\right] \lambda } \\
& -\underbrace{\left[T\left(P \frac{\theta \lambda}{2}+C_{h} \frac{\lambda}{2}+(1-\beta)\left(i_{e} P \lambda \frac{\theta}{2}+i_{e} P \lambda\right)\right)+\frac{1}{T}(A)\right]}_{A T C_{2.3}(T)}
\end{aligned}
$$

Maximising $A T C_{2.3}(T)$ is equivalent to minimising $A T C_{2.3}(T)$. For notational convenience we consider:

$$
\operatorname{ATC}_{2.3}(T)=T \rho_{1}+\frac{1}{T} \rho_{2}
$$


where $\rho_{1}=P \frac{\theta \lambda}{2}+C_{h} \frac{\lambda}{2}+(1-\beta) i_{e} P \lambda\left(\frac{\theta}{2}+1\right)$ and $\rho_{2}=A>0$

The first partial derivative of $A T C_{2.3}(T)$ with reference to $T$ yields to:

$$
\frac{\delta A T C_{2.3}(T)}{\delta T}=-\frac{1}{T^{2}} \rho_{2}+\rho_{1}
$$

After setting this equation to 0 , we obtain:

$$
T_{(2.3)}=\sqrt{\frac{\rho_{2}}{\rho_{1}}}
$$

Again, the value provided in Eq. (37) is the unique global optimum solution of the inventory problem. This has been established in "Appendix B" using the approach of Pentico et al. (2009).

\subsection{The model with backordering}

The optimal solutions for $T$ and $F$ are determined in such a way that the annual total profit of the inventory model with backordering is optimised.

Case 1: By using $\left(e^{x} \approx 1+x+\frac{x^{2}}{2}\right)$ term, substituting it into Eq. (15), and simplifying the expression we obtain:

$$
\begin{aligned}
\operatorname{ATP}_{1}(T, F)= & {\left[P-C_{p}-i_{k} C_{p} \frac{(n+1)}{2 n} L\right] \lambda } \\
& -\underbrace{\left[F^{2} T\left(P \frac{\theta \lambda}{2}+\frac{\left(C_{h}+C_{b}\right) \lambda}{2}\right)+\frac{A}{T}+T\left(C_{b} \frac{\lambda}{2}\right)-F T\left(C_{b} \lambda\right)\right]}_{A T C_{1}(T, F)}
\end{aligned}
$$

Maximising the term $\operatorname{ATP}_{1}(T, F)$ is equivalent to minimising the term $\operatorname{ATC}_{1}(T, F)$. For notational convenience we consider:

$$
A T C_{1}(T, F)=F^{2} T \varphi_{1}+\frac{\varphi_{2}}{T}+T\left(\frac{\varphi_{3}}{2}\right)-F T\left(\varphi_{3}\right)
$$

where $\varphi_{1}=P \frac{\theta \lambda}{2}+\frac{\left(C_{h}+C_{b}\right) \lambda}{2}>0, \varphi_{2}=A>0$, and $\varphi_{3}=C_{b} \lambda>0$

The first partial derivatives of $A T P_{1}(T, F)$ with reference to $T$ and $F$ yield:

$$
\begin{gathered}
\frac{\delta A T C_{1}(T, F)}{\delta T}=F^{2} \varphi_{1}-\frac{\varphi_{2}}{T^{2}}+\frac{\varphi_{3}}{2}-F \varphi_{3} \\
\frac{\delta A T C_{1}(T, F)}{\delta F}=2 F T \varphi_{1}-T \varphi_{3}
\end{gathered}
$$

After setting these equations to 0 , we obtain:

$$
F_{(1)}=\frac{\varphi_{3}}{2 \varphi_{1}},
$$

and 


$$
T_{(1)}=\sqrt{\frac{4 \varphi_{1} \varphi_{2}}{2 \varphi_{1} \varphi_{3}-\varphi_{3}^{2}}}
$$

The expressions obtained in Eqs. (42) and (43) are the unique global optimum solutions to the inventory problem. This has been demonstrated in "Appendix C" using the approach of Pentico et al. (2009).

Case 2.1: By using $e^{x} \approx 1+x+\frac{x^{2}}{2}$ term, substituting it into Eq. (21), and simplifying the expression we obtain:

$$
\begin{aligned}
A T P_{2.1}(T, F)= & {\left[P-C_{p}-\beta i_{k} C_{p} \frac{(n+1)}{2 n} L+i_{e}(1-\beta) P M\right] \lambda } \\
& -\left[\begin{array}{c}
F^{2} T\left(P \frac{\theta \lambda}{2}+C_{h} \frac{\lambda}{2}+C_{b} \frac{\lambda}{2}+\frac{i_{k} C_{p} \lambda}{2}\right) \\
+\frac{1}{T}\left(A-i_{e}(1-\beta) P \lambda\left(\frac{\theta M^{2}}{2}-M\right)+\frac{i_{k} C_{p} \lambda M^{2}}{2}\right) \\
-F\left(i_{k} C_{p} \lambda M-i_{e}(1-\beta) P \lambda M\right)+T\left(C_{b} \frac{\lambda}{2}\right)-F T\left(C_{b} \lambda\right)
\end{array}\right]
\end{aligned}
$$

Maximising the term $A T P_{2.1}(T, F)$ is equivalent to minimising the term $A T C_{2.1}(T, F)$. For notational convenience we consider:

$$
A T C_{2.1}(T, F)=F^{2} T \phi_{1}+\frac{1}{T} \phi_{2}-F \phi_{3}+T \frac{\phi_{4}}{2}-F T \phi_{4}
$$

where $\phi_{1}=P \frac{\theta \lambda}{2}+\frac{\left(C_{h}+C_{b}\right) \lambda}{2}+\frac{i_{k} C_{p} \lambda}{2}>0, \phi_{2}=A+\frac{i_{k} C_{p} \lambda M^{2}}{2}+i_{e}(1-\beta) P \lambda\left(\frac{\theta M^{2}}{2}-M\right)>0$, $\phi_{3}=\left(i_{k} C_{p}-i_{e}(1-\beta) P\right) \lambda M>0$, and $\phi_{4}=C_{b} \lambda>0$.

The first partial derivatives of $A T C_{2.1}(T, F)$ with reference to $T$ and $F$ yield:

$$
\begin{gathered}
\frac{\delta A T C_{2.1}(T, F)}{\delta T}=F^{2} \phi_{1}-\frac{1}{T^{2}} \phi_{2}+\frac{\phi_{4}}{2}-F \phi_{4} \\
\frac{\delta A T C_{1}(T, F)}{\delta F}=2 F T \phi_{1}-\phi_{3}-T \phi_{4}
\end{gathered}
$$

After setting these equations to 0 , we obtain:

$$
F_{(2.1)}=\frac{\phi_{4}}{2 \phi_{1}}+\frac{\phi_{3}}{2 \phi_{1}} \sqrt{\frac{2 \phi_{1} \phi_{4}-\phi_{4}^{2}}{4 \phi_{1} \phi_{2}-\phi_{3}^{2}}}
$$

and

$$
T_{(2.1)}=\sqrt{\frac{4 \phi_{1} \phi_{2}-\phi_{3}^{2}}{2 \phi_{1} \phi_{4}-\phi_{4}^{2}}}
$$


The expressions obtained in Eqs. (48) and (49) are the unique global optimum solutions to the inventory problem. The proof can be found in "Appendix C" using Pentico et al.'s (2009) approach.

Case 2.2: Substituting $e^{x} \approx 1+x+\frac{x^{2}}{2}$ into Eq. (21) and simplifying it we obtain:

$$
\begin{aligned}
A T P_{2.2}(T, F)= & {\left[P-C_{p}+(1-\beta) i_{e} P \lambda M-\beta i_{k} C_{p} \lambda \frac{(n+1)}{2 n} L\right] } \\
& -\underbrace{\left[\begin{array}{r}
F^{2} T\left(P \frac{\lambda \theta}{2}+C_{h} \frac{\lambda}{2}+C_{b} \frac{\lambda}{2}\right)+\frac{1}{T}\left(A+(1-\beta) i_{e} P \lambda\left(M-\frac{\theta M^{2}}{2}\right)\right) \\
+T\left(C_{b} \frac{\lambda}{2}\right)-F\left(-(1-\beta) i_{e} P \lambda M+(1-\beta) i_{k} C_{p} \lambda M\right)-F T\left(C_{b} \lambda\right)
\end{array}\right]}_{A T C_{2.2}(T, F)}
\end{aligned}
$$

Maximising the expression $A T P_{2.2}(T, F)$ is equivalent to minimising the expression $A T C_{2.2}(T, F)$. For notational convenience we consider:

$$
A T C_{2.2}(T, F)=F^{2} T v_{1}+\frac{1}{T} v_{2}-F v_{3}+T \frac{v_{4}}{2}-F T v_{4}
$$

where $\quad v_{1}=P \frac{\lambda \theta}{2}+\frac{\left(C_{h}+C_{b}\right) \lambda}{2}>0, \quad v_{2}=A+i_{e}(1-\beta) P \lambda\left(M-\frac{\theta M^{2}}{2}\right)>0$, $\nu_{3}=(1-\beta) \lambda M \times\left(i_{k} C_{p}-i_{e} P\right)>0$, and $v_{4}=C_{b} \lambda>0$.

The first partial derivatives of $A T C_{2.1}(T, F)$ with reference to $T$ and $F$ yield:

$$
\begin{gathered}
\frac{\delta A T C_{2.2}(T, F)}{\delta T}=F^{2} v_{1}-\frac{1}{T^{2}} v_{2}+\frac{v_{4}}{2}-F v_{4} \\
\frac{\delta A T C_{2.2}(T, F)}{\delta F}=2 F T v_{1}-v_{3}-T v_{4}
\end{gathered}
$$

After setting these equations to 0 , we obtain:

$$
F_{(2.2)}=\frac{v_{4}}{2 v_{1}}+\frac{v_{3}}{2 v_{1}} \sqrt{\frac{2 v_{1} v_{4}-v_{4}^{2}}{4 v_{1} v_{2}-v_{3}^{2}}}
$$

and

$$
T_{(2.2)}=\sqrt{\frac{4 v_{1} v_{2}-v_{3}^{2}}{2 v_{1} v_{4}-v_{4}^{2}}}
$$

The expressions obtained in Eqs. (54) and (55) are the unique global optimum solutions to the inventory problem. This is illustrated in "Appendix C" using the approach of Pentico et al. (2009).

Case 2.3: Substituting $e^{x} \approx 1+x+\frac{x^{2}}{2}$ into Eq. (24), and simplifying it we obtain: 


$$
\begin{aligned}
A T P_{2.3}(T, F)= & {\left[P-C_{p}-\beta i_{k} C_{p} \frac{(n+1)}{2 n} L+(1-\beta) i_{e} P \lambda M\right] \lambda } \\
& -\left[\begin{array}{r}
\left.F^{2} T\left(P \frac{\theta \lambda}{2}+\frac{\left(C_{h}+C_{b}\right) \lambda}{2}+(1-\beta) i_{e} P \lambda \frac{\theta}{2}+(1-\beta) i_{e} P \lambda\right)+\frac{A}{T}\right] \\
-F\left[(1-\beta) i_{e} P \lambda\right]+T\left(C_{b} \frac{\lambda}{2}\right)-F T\left(C_{b} \lambda\right)
\end{array}\right]
\end{aligned}
$$

Maximising the expression $A T C_{2.3}(T, F)$ is equivalent to minimising the expression $A T C_{2.3}(T, F)$. For notational convenience we consider:

$$
A T C_{2.3}(T, F)=F^{2} T \rho_{1}+\frac{1}{T} \rho_{2}-F \rho_{3}+T \frac{\rho_{4}}{2}-F T \rho_{4}
$$

where

$$
\rho_{1}=P \frac{\theta \lambda}{2}+\frac{\left(C_{h}+C_{b}\right) \lambda}{2}+(1-\beta) i_{e} P \lambda \frac{\theta}{2}+(1-\beta) i_{e} P \lambda>0,
$$$$
\rho_{2}=A>0
$$
,$\rho_{3}=(1-\beta) i_{e} P \lambda>0$, and $\rho_{4} \stackrel{2}{=} C_{b} \lambda>0$.

The first partial derivatives of $A T C_{2.3}(T, F)$ with reference to $T$ and $F$ are obtained as follows:

$$
\begin{gathered}
\frac{\delta A T C_{2.3}(T, F)}{\delta T}=F^{2} \rho_{1}-\frac{1}{T^{2}} \rho_{2}+\frac{\rho_{4}}{2}-F \rho_{4} \\
\frac{\delta A T C_{2.3}(T, F)}{\delta F}=2 F T \rho_{1}-\rho_{3}-T \rho_{4}
\end{gathered}
$$

Further, setting these equations to 0 we obtain:

$$
F_{(2.3)}=\frac{\rho_{4}}{2 \rho_{1}}+\frac{\rho_{3}}{2 \rho_{1}} \sqrt{\frac{2 \rho_{1} \rho_{4}-\rho_{4}^{2}}{4 \rho_{1} \rho_{2}-\rho_{3}^{2}}}
$$

and

$$
T_{(2.3)}=\sqrt{\frac{4 \rho_{1} \rho_{2}-\rho_{3}^{2}}{2 \rho_{1} \rho_{4}-\rho_{4}^{2}}}
$$

The expressions obtained in Eqs. (60) and (61) are the unique global optimum solutions of the problem. This is illustrated in "Appendix C" using the approach of Pentico et al. (2009).

\subsection{Inspection policy}

Let us assume that an inspection is performed in the inventory system, which is decreasing with the rate of deterioration $\theta$ during the replenishment cycle time $[0, T]$. At the beginning of each period, $Q$ units of product are available for selling to customers. At time 


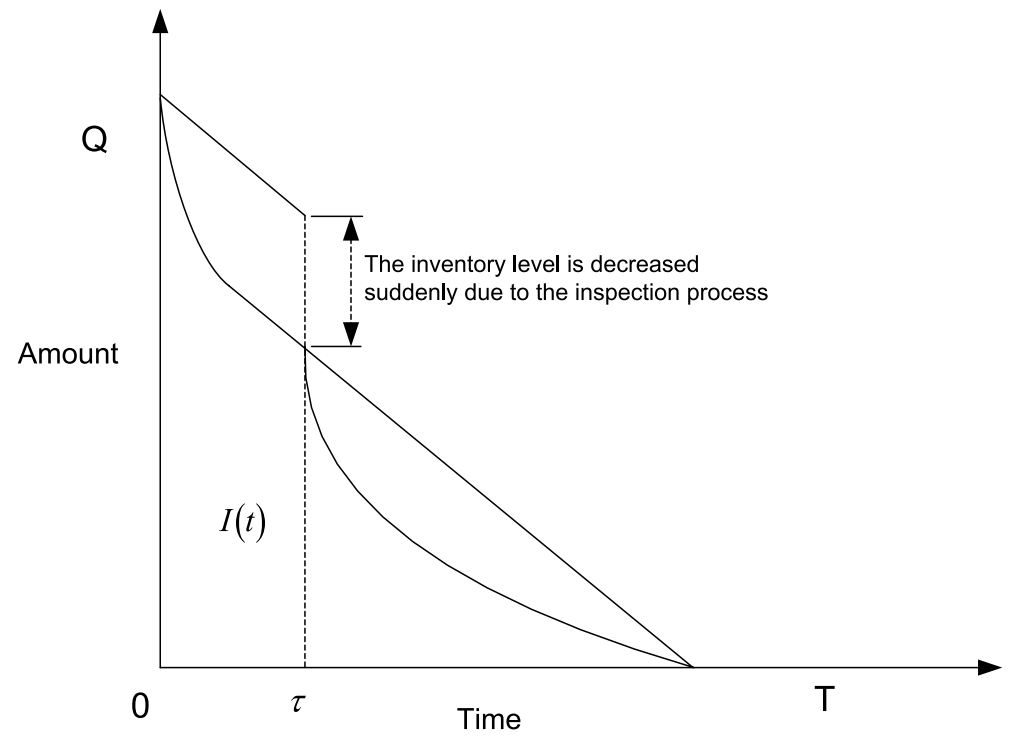

Fig. 10 The inventory level when one inspection is performed during the replenishment cycle

$\tau(0<\tau<T)$ an inspection is performed, and the deteriorated products are screened out since the beginning of period until $\tau$. Figure 10 illustrates the inventory level along the replenishment cycle. A similar assumption considering inspection policy for both serviceable and deteriorating items is found in Tai et al. (2016). In this article, it is assumed that the inspection process is performed in the inventory system without any error during detection of deteriorated products aiming to formulate a model for defining the optimal inspection time.

Based on the values of $T$ and $Q$ it is required to consider the following two possible states:

State $1 Q<\lambda T$ : In this state, there isn't a surplus product because of inventory shortage

State $2 Q \geq \lambda T$ : In this state, there are surplus products at time $T$. The value of $Q$ can be reduced to $\lambda T$ or less than $\lambda T$ to reduce the holding cost. Here the value of $\tau$ is defined in such a way that minimises the length of the inventory cycle. The optimal inspection time, $\tau^{*}$, is determined by solving the following equation (see “Appendix D");

$$
\left[\left(\lambda \theta^{2}\right) \tau^{* 3}-\left(Q \theta^{2}+3 \lambda \theta\right) \tau^{* 2}+(2 Q \theta+4 \lambda) \tau^{*}-2 Q\right]=0
$$

The annual total profits are presented for the following four possible cases:

$$
\begin{cases}A T P_{1} & \text { if } T<T_{w} \\ A T P_{2.1} & \text { if } M \leq T<\frac{M}{\beta} \\ A T P_{2.2} & \text { if } \frac{M}{\beta} \leq T \\ A T P_{2.3} & \text { if } T<M\end{cases}
$$


where

$$
\begin{aligned}
A T P_{1}= & \underbrace{P\left(\frac{\lambda}{\theta} \frac{\left(1-e^{-\theta \tau}\right)}{T}\right)-\left(\frac{A}{T}+C_{h} \frac{(2 Q-\lambda \tau) \tau}{2 T}+C_{p} \lambda+i_{k} C_{p} \lambda \frac{(n+1)}{2 n} L\right)}_{\text {over }[0, \tau]} \\
& +\underbrace{\left(v\left((Q-\lambda \tau) e^{-\theta \tau}, T-\tau\right)-(D+d(Q-\lambda \tau))\right)}_{\text {over }[\tau, T]}
\end{aligned}
$$

$$
\begin{aligned}
A T P_{2.1}= & P\left(\frac{\lambda}{\theta} \frac{\left(1-e^{-\theta \tau}\right)}{T}+(1-\beta) i_{e} \frac{\lambda}{\theta} \frac{\left(1-e^{-\theta M}\right)}{T}\right) \\
& -\underbrace{\left(\frac{A}{T}+C_{h} \frac{(2 Q-\lambda \tau) \tau}{2 T}+C_{p} \lambda+\beta i_{k} C_{p} \lambda \frac{(n+1)}{2 n} L+i_{k} C_{p} \lambda \frac{(T-M)^{2}}{2 T}\right)}_{\text {over }[0, \tau]} \\
& +\underbrace{\left(v\left((Q-\lambda \tau) e^{-\theta \tau}, T-\tau\right)-(D+d(Q-\lambda \tau))\right)}_{\text {over }[\tau, T]}
\end{aligned}
$$

$$
\begin{aligned}
A T P_{2.2}= & P\left(\frac{\lambda}{\theta} \frac{\left(1-e^{-\theta \tau}\right)}{T}+(1-\beta) i_{e} P \frac{\lambda}{\theta} \frac{\left(1-e^{-\theta M}\right)}{T}\right) \\
& \underbrace{\left(\frac{A}{T}+C_{h} \frac{(2 Q-\lambda \tau) \tau}{2 T}+C_{p} \lambda+\beta i_{k} C_{p} \lambda \frac{(n+1)}{2 n} L\right)}_{\text {over }[0, \tau]} \\
& +\underbrace{\left(v\left((Q-\lambda \tau) e^{-\theta \tau}, T-\tau\right)-(D+d(Q-\lambda \tau))\right)}_{\text {over }[\tau, T]}
\end{aligned}
$$

$$
\begin{aligned}
A T P_{2.3}= & P\left[\frac{\lambda}{\theta} \frac{\left(1-e^{-\theta \tau}\right)}{T}+(1-\beta) \times\left(i_{e} P \frac{\lambda}{\theta} \frac{\left(1-e^{-\theta F}\right)}{T}+i_{e} P \lambda(M-T)\right)\right] \\
-\left(\frac{A}{T}+C_{h} \frac{(2 Q-\lambda \tau) \tau}{2 T}+C_{p} \lambda+\beta i_{k} C_{p} \lambda \frac{(n+1)}{2 n} L\right) & \underbrace{\left(v\left((Q-\lambda \tau) e^{-\theta \tau}\right)-(D+d(Q-\lambda \tau))\right)}_{\text {over }[0, \tau]}
\end{aligned}
$$


For notational convenience, we define the inventory level of serviceable products at the time of inspection as $q$ in the above expressions (where $q=(Q-\lambda \tau) e^{-\theta \tau}$ ). Based on the value of $q$ the following three sub-states are possible:

Sub-state 1: $\lambda(T-\tau)<q$ : In this sub-state, product replacement service is offered by the supplier for the unsold serviceable products at a price of $C_{p}$. Therefore, we obtain:

$$
v(q, T-\tau)=P\left(\frac{\lambda}{\theta} \frac{\left(1-e^{-\theta(T-\tau)}\right)}{T}\right)-C_{h} \frac{(2 q-\lambda(T-\tau)) \times(T-\tau)}{2}+C_{p} \frac{\left(q-\lambda(T-\tau) e^{-\theta(T-\tau)}\right)}{T}
$$

Sub-state 2: $\lambda(T-\tau)=q$ : In this sub-state, there isn't any unsold serviceable product since the inventory level reaches to zero when a replenishment cycle ends. Therefore, we have:

$$
v(q, T-\tau)=P\left(\frac{\lambda}{\theta} \frac{\left(1-e^{-\theta(T-\tau)}\right)}{T}\right)-C_{h} \frac{q(T-\tau)}{2 T}
$$

Sub-state 3: $\lambda(T-\tau)>q$ : In this sub-state, shortage of the products occurs, and $\lambda(T-\tau)-q$ of products are backordered. Therefore, we have:

$$
\begin{array}{r}
v(q, T-\tau)=P\left(\frac{\lambda}{\theta} \frac{\left(1-e^{-\frac{\theta q}{\lambda}}\right)}{T}+\frac{\lambda(T-\tau)-q}{T}\right) \\
-\left[C_{h} \frac{q^{2}}{2 \lambda T}+C_{p} \frac{[\lambda(T-\tau)-q]}{T}+C_{b} \frac{[\lambda(T-\tau)-q]^{2}}{2 \lambda T}\right]
\end{array}
$$

\begin{tabular}{|c|c|c|c|c|}
\hline \multirow[t]{2}{*}{ Shortage } & \multirow[t]{2}{*}{ Cases } & \multicolumn{3}{|c|}{ Optimal solution in each case } \\
\hline & & $F_{(i)}$ & $T_{(i)}$ & $A T P_{(i)}$ \\
\hline \multirow[t]{4}{*}{ Without shortage } & Case $1 T<T_{w}$ & - & $T_{(1)}=0.9325$ & Undefined \\
\hline & $\begin{array}{l}\text { Case } 2.1 T_{w}<T \text { and } \\
\quad \beta T \leq M \leq T\end{array}$ & - & $T_{(2.1)}=0.7510$ & $A T P_{(2.1)}=715.4255$ \\
\hline & $\begin{array}{l}\text { Case } 2.2 T_{w}<T \text { and } \\
\quad M \leq \beta T\end{array}$ & - & $T_{(2.2)}=0.9997$ & $A T P_{(2.2)}=660.15$ \\
\hline & $\begin{array}{l}\text { Case } 2.3 T_{w}<T \text { and } \\
\quad T \leq M\end{array}$ & - & $T_{(2.3)}=0.8088$ & Undefined \\
\hline \multicolumn{5}{|c|}{$\begin{array}{l}A T P^{*}=\operatorname{Max}\left\{A T P_{i}\right\} \rightarrow A T P^{*}=A T P_{2.1}=715.4255 \\
T^{*}=T_{(2.1)}=0.7510\end{array}$} \\
\hline \multirow[t]{4}{*}{ With full backordering } & Case $1 T<T_{w}$ & $F_{(1)}=0.6849$ & $T_{(1)}=1.1267$ & Undefined \\
\hline & $\begin{array}{l}\text { Case } 2.1 T_{w}<T \text { and } \\
\quad \beta F T \leq M \leq F T\end{array}$ & $F_{(2.1)}=0.6336$ & $T_{(2.1)}=0.9656$ & $A T P_{(2.1)}=843.7413$ \\
\hline & $\begin{array}{l}\text { Case } 2.2 T_{w}<T \text { and } \\
\quad M \leq \beta F T\end{array}$ & $F_{(2.2)}=0.6906$ & $T_{(2.2)}=1.2079$ & $A T P_{(2.2)}=745.3479$ \\
\hline & $\begin{array}{l}\text { Case } 2.3 T_{w}<T \text { and } \\
\quad F T \leq M\end{array}$ & $F_{(2.3)}=0.6655$ & $T_{(2.3)}=1.0214$ & Undefined \\
\hline \multicolumn{5}{|c|}{$A T P^{*}=\operatorname{Max}\left\{A T P_{i}\right\} \rightarrow A T P^{*}=A T P_{2.1}=843.7413\left(T^{*}, F^{*}\right)=\left(T_{(2.1)}, F_{(2.1)}\right)=(0.9656,0.6336)$} \\
\hline \multicolumn{5}{|c|}{ Undefined solution when the value of $T_{(i)}$ doesn't fit to the range specified in column 1} \\
\hline
\end{tabular}

Table 2 Optimal solutions to the models with and without inventory shortage 
Table 3 Sensitivity analysis

\begin{tabular}{|c|c|c|}
\hline Parameters & $T^{*}$ & $A T P$ \\
\hline \multicolumn{3}{|c|}{ (a) For the model without inventory shortage } \\
\hline \multicolumn{3}{|l|}{$\theta$} \\
\hline$\theta=0.01$ & $T_{2.1}^{*}=0.7685$ & $A T P_{2.1}=729.7681$ \\
\hline$\theta=0.02$ & $T_{2.1}^{*}=0.7510$ & $A T P_{2.1}=715.4255$ \\
\hline$\theta=0.03$ & $T_{2.1}^{*}=0.7346$ & $A T P_{2.1}=701.3987$ \\
\hline$\theta=0.04$ & $T_{2.1}^{*}=0.7193$ & $A T P_{2.1}=687.6670$ \\
\hline$\theta=0.05$ & $T_{2.1}^{*}=0.7048$ & $A T P_{2.1}=674.2121$ \\
\hline \multicolumn{3}{|l|}{$\beta$} \\
\hline$\beta=0.01$ & $T_{2.1}^{*}=0.6894$ & $A T P_{2.1}=780.9491$ \\
\hline$\beta=0.2$ & $T_{2.1}^{*}=0.7139$ & $A T P_{2.1}=755.0212$ \\
\hline$\beta=0.5$ & $T_{2.1}^{*}=0.7510$ & $A T P_{2.1}=715.4255$ \\
\hline$\beta=0.8$ & $T_{2.1}^{*}=0.7863$ & $A T P_{2.1}=677.2712$ \\
\hline$\beta=1$ & $T_{2.2}^{*}=0.9325$ & $A T P_{2.1}=563.8097$ \\
\hline \multicolumn{3}{|l|}{$M$} \\
\hline$M=0.2$ & $T_{2.2}^{*}=0.9668$ & $A T P_{2.2}=679.1049$ \\
\hline$M=0.4$ & $T_{2.1}^{*}=0.7510$ & $A T P_{2.1}=715.4255$ \\
\hline$M=0.6$ & $T_{2.1}^{*}=0.7613$ & $A T P_{2.1}=756.9121$ \\
\hline$M=0.8$ & $T_{2.1}^{*}=0.7872$ & $A T P_{2.1}=785.5849$ \\
\hline$M=1$ & $T_{2.3}^{*}=0.8088$ & $A T P_{2.3}=616.7868$ \\
\hline \multicolumn{3}{|l|}{$W$} \\
\hline$W=50$ & $T_{2.1}^{*}=0.7510$ & $A T P_{2.1}=715.4255$ \\
\hline$W=150$ & $T_{2.1}^{*}=0.7510$ & $A T P_{2.1}=715.4255$ \\
\hline$W=250$ & $T_{1}^{*}=0.9325$ & $A T P_{1}=683.8097$ \\
\hline Parameters & $F^{*}$ & $A T P^{*}$ \\
\hline
\end{tabular}

(b) For the model with inventory shortage (i.e. full backordering)

$\theta$

\begin{tabular}{|c|c|c|c|}
\hline$\theta=0.01$ & $T_{2.1}^{*}=0.9791$ & $F_{2.1}^{*}=0.6448$ & $A T P_{2.1}=837.7673$ \\
\hline$\theta=0.02$ & $T_{2.1}^{*}=0.9656$ & $F_{2.1}^{*}=0.6336$ & $A T P_{2.1}=830.2413$ \\
\hline$\theta=0.03$ & $T_{2.1}^{*}=0.9530$ & $F_{2.1}^{*}=0.6227$ & $A T P_{2.1}=823.0657$ \\
\hline$\theta=0.04$ & $T_{2.1}^{*}=0.9415$ & $F_{2.1}^{*}=0.6123$ & $A T P_{2.1}=816.2144$ \\
\hline$\theta=0.05$ & $T_{2.1}^{*}=0.9306$ & $F_{2.1}^{*}=0.6021$ & $A T P_{2.1}=809.6641$ \\
\hline \multicolumn{4}{|c|}{$\beta$} \\
\hline$\beta=0.01$ & $T_{2.1}^{*}=0.8879$ & $F_{2.1}^{*}=0.6164$ & $A T P_{2.1}=898.2057$ \\
\hline$\beta=0.2$ & $T_{2.1}^{*}=0.9190$ & $F_{2.1}^{*}=0.6234$ & $A T P_{2.1}=871.3795$ \\
\hline$\beta=0.5$ & $T_{2.1}^{*}=0.9656$ & $F_{2.1}^{*}=0.6336$ & $A T P_{2.1}=830.2413$ \\
\hline$\beta=0.8$ & $T_{2.2}^{*}=1.1599$ & $F_{2.2}^{*}=0.6873$ & $A T P_{2.2}=787.6094$ \\
\hline$\beta=1$ & $T_{2.2}^{*}=1.1267$ & $F_{2.2}^{*}=0.6849$ & $A T P_{2.2}=776.2458$ \\
\hline \multicolumn{4}{|c|}{$M$} \\
\hline$M=0.2$ & $T_{2.2}^{*}=1.1681$ & $F_{2.2}^{*}=0.6879$ & $A T P_{2.2}=797.9779$ \\
\hline$M=0.4$ & $T_{2.1}^{*}=0.9656$ & $F_{2.1}^{*}=0.6336$ & $A T P_{2.1}=830.2413$ \\
\hline$M=0.6$ & $T_{2.1}^{*}=0.9765$ & $F_{2.1}^{*}=0.6487$ & $A T P_{2.1}=862.3991$ \\
\hline$M=0.8$ & $T_{2.3}^{*}=1.0214$ & $F_{2.3}^{*}=0.6655$ & $A T P_{2.3}=897.8871$ \\
\hline$M=1$ & $T_{2.3}^{*}=1.0214$ & $F_{2.3}^{*}=0.6655$ & $A T P_{2.3}=916.6371$ \\
\hline
\end{tabular}


Table 3 (continued)

\begin{tabular}{llll}
\hline Parameters & $T^{*}$ & $F^{*}$ & $A T P^{*}$ \\
\hline$W$ & & & \\
$W=50$ & $T_{2.1}^{*}=0.9656$ & $F_{2.1}^{*}=0.6336$ & $A T P_{2.1}=830.2413$ \\
$W=150$ & $T_{2.1}^{*}=0.9656$ & $F_{2.1}^{*}=0.6336$ & $A T P_{2.1}=830.2413$ \\
$W=250$ & $T_{2.1}^{*}=0.9656$ & $F_{2.1}^{*}=0.6336$ & $A T P_{2.1}=830.2413$ \\
$W=350$ & $T_{1}^{*}=1.1267$ & $F_{1}^{*}=0.6849$ & $A T P_{1}=776.2457$ \\
\hline
\end{tabular}

\section{Numerical illustrations, results and discussion}

This section elucidates efficacy of the proposed inventory models and its solution method through several examples. Examples \#1 and \#2 are used to demonstrate the efficacy of the models without inspection policy during the replenishment cycle. Sensitivity analysis of the optimal solution is subsequently examined. Examples \#3 and \#4 are used to demonstrate the efficacy of the inventory models under inspection policy with a focus on sensitivity analysis of some key parameters.

Example \#1 The following parameters are adopted from Taleizadeh et al. (2013b): $\lambda=250, A=250 \$, P=\$ 15 /$ unit, $C_{p}=\$ 10 /$ unit, $C_{b}=\$ 5 /$ unit/year, $C_{h}=\$ 2 /$ unit/year, $M=0.4$ year, $W=150$ units, $\theta=0.02, i_{k}=\$ 0.1 /$ year, $i_{e}=\$ 0.05 /$ year, $n=5, \beta=0.5$ and $L=0.2$ year.

The optimal variables of each case are computed using the proposed solution method (Table 2). If the value of $T_{(i)}$ fits to the range specified for each case, the value of annual total profit is calculated; otherwise undefined value is obtained for each case which doesn't satisfy the possibility. Afterwards, the optimal solution is obtained by comparing the annual total profit values from the solutions obtained and selecting the maximum value.

Example \#2 Impact of some parameter values on the optimal solutions is studied. The same data as that of Example \#1 are used in this example. Table 3 illustrates the effects of changing the parameters on $T$ and ATP for the models without (Table 3a) and with inventory shortage (Table $3 b$ ) respectively.

The following observations are drawn from the results:

- The $A T P$ and $T^{*}$ values decrease in both the models while there is an increase in the values of $\theta$. This indicates that the less is the deterioration rate, the more will be the annual total profit. The values of $F^{*}$ decrease while the values of $\theta$ increase.

- When there is an increase in the values of $\beta$, the $A T P$ values decrease and $T$ values increase in both the models. This indicates that the more payment is made before the delivery time, the less annual profit will be achieved. Moreover, the value of $F^{*}$ increases with increase in the values of $\beta$.

- No specific change is found by increasing the value of $M$. However, in both the models, with the low value of $M$, Case 2.2 results in the optimal solution. Again, the optimal 
Table 4 Optimal results of the model with respect to $\mathrm{Q}$

\begin{tabular}{llll}
\hline$Q$ & $\tau^{*}$ & $A T P(Q, T)$ & $A T P^{*}\left(Q, T, \tau^{*}\right)$ \\
\hline 187.7498 & 0.3748 & 636.60 & 720.1343 \\
200 & 0.3992 & 460.248 & 690.9591 \\
205 & 0.4092 & 388.2714 & 678.9255 \\
210 & 0.4191 & 316.2940 & 666.8325 \\
215 & 0.4291 & 244.3166 & 654.6581 \\
220 & 0.4390 & 172.3391 & 642.4247 \\
225 & 0.4490 & 100.3617 & 630.1093 \\
\hline
\end{tabular}

solution is obtained in Case 2.1 by increasing the value of $M$. With a high value of $M$ Case 2.3 results in optimal solution.

- In both the models the optimal solutions do not change with an increase of the threshold value $W$. It is observed that just after the threshold value of $W$, the value of ATP decreases and optimal solution is obtained when all the purchasing costs are paid as prepayments. This indicates that a lower value of ordering threshold causes higher value of $A T P$. Additionally, $W$ remains unchanged up to a larger value in the model with product shortage than that of the model without shortage. This means that the retailer earns more profit with a smaller value of $W$ when inventory shortage is not allowed.

Example \#3 The data used in this example are the same as that of Example \#1, except that the cases include an inspection policy during the replenishment cycle. Let $D=2 /$ cycle, and $d=0.05 /$ unit. It is assumed that the inventory level is at a value of $Q=Q^{*}=187.7498,200,205,210,215,220$ and 225 as seven cases. Since there is no inspection when inventory shortage occurs, we investigate the situation when there is no inventory shortage. In Example 1, we demonstrate that optimal solution happens in Case 2.1. (i.e. $M \leq T<\frac{M}{\beta}$ ). The optimal inspection time ( $\left.\tau^{*}\right)$ is calculated through Eq. (62). The optimal profit per unit is computed with respect to $Q$ and $\tau^{*}$ in each. This follows computation of the annual profit per unit with no inspection policy. The results are compared with the net profit per unit in a situation with inspection policy. The results are illustrated in Table 4.

Table 5 Impact of some parameters on the optimal decisions

\begin{tabular}{llll}
\hline Parameters & $\tau^{*}$ & $T^{*}$ & $A T P^{*}\left(T, \tau^{*}\right)$ \\
\hline$\theta$ & & & \\
$\theta=0.01$ & 0.3839 & 0.7685 & 736.6043 \\
$\theta=0.02$ & 0.3748 & 0.7510 & 720.1343 \\
$\theta=0.03$ & 0.3663 & 0.7346 & 703.4831 \\
$d$ & & & \\
$d=0$ & 0.3748 & 0.7510 & 708.1855 \\
$d=0.05$ & 0.3748 & 0.7510 & 720.1343 \\
$d=0.1$ & 0.3748 & 0.7510 & 698.7806 \\
\hline
\end{tabular}


The results in Table 4 indicate that inclusion of the inspection policy is better when compared with no inspection policy. This is because that the net profit significantly increases under inspection policy. In Table 4 the column $\operatorname{ATP}^{*}\left(Q, T, \tau^{*}\right)$ tends to decrease while $Q$ increases.

Example \#4 In this example the effects of some parameters, e.g. $\theta$ and $d$, on the optimal solutions of the proposed model with inspection process are analysed. The same data as that of Example \#3 are used in this example.

Table 5 illustrates that as $\theta$ increases, the values of $\tau^{*}, T^{*}$ and $A T P^{*}\left(T, \tau^{*}\right)$ decrease. This indicates that a higher deterioration rate causes lowering the profit, lower cycle time and lower inspection time. The reason is that a higher value of deteriorated items may result in higher cost as the inspection cost, reordering cost and holding cost increase. Further, Table 5 illustrates that when $d$ increases, the net profit tends to decrease, but the values of $T^{*}$ and $\tau^{*}$ remain constant. It is reasonable because $d$ doesn't play a role in the optimality of $T^{*}$ and $\tau^{*}$.

\subsection{Managerial implications}

The proposed inventory model and its solution method presented in this study provide powerful tools for the retail managers. Through the use of the proposed model, the managers will have a better control of their inventory in the retail stores when a mixture of serviceable and deteriorating products will be sold to the consumers under multiple prepayments scheme, partial trade credits, payments linked to order quantity, inspection policy, no inventory shortage, with inventory shortage and full backordering, and any combination of these cases.

The analyses reveal that the less is the deterioration rate, the more is the annual total profit. Therefore, in the retail stores, the managers are required to focus on the perishability of the products. The analyses further reveal that when more prepayments are made less annual total profit is earned. Therefore, during the prepayments, the managers should try to keep the prepayment amount and frequency as minimum as possible. Further, a lower ordering threshold value results in a higher annual total profit. This means that the retailer earns more profit with a comparatively smaller ordering threshold value when inventory shortage is not allowed.

The analyses reveal that it is important for the managers to include an inspection policy in their inventory system as the inspection policy increases the net annual total profit significantly. Further, this study provides a support to the managers regarding number of deteriorated products stored in the retail inventory. A high number of deteriorating products results in a high inspection cost, reordering cost and holding cost. Further, a comparatively higher deterioration rate causes low profit, low cycle time and low inspection time. Thus, the managers are required to consider the deterioration rate of the stored products. The inventory models will assist the managers to make appropriate decisions when the net profit of the retail store will tend to decrease and inspection booking cost will increase while keeping constant the optimal length of the replenishment cycle and optimal inspection time. 


\section{Conclusions}

The earlier inventory models considered monitoring of the deteriorating products instantaneously, which doesn't fit to the realistic circumstances. This is because the products in stores may gradually deteriorate during the storage period, and these products are sold together with serviceable products to consumers thereby causing frequent product returns. To ameliorate this situation, in this study, inventory model under hybrid payment schemes is proposed under a situation where a portion of the deteriorating products are mixed with a portion of serviceable products for selling to consumers (i.e. mixed sale of products). A hybrid payment strategy linked to order quantity is considered that involves multiple prepayments and partial trade credit. Impact of an inspection policy on the mixed sale of products under the hybrid payment scheme is investigated. A new solution method for the inventory models is proposed. The solution method identifies optimal annual total profit with mixed sales assuming no inventory shortage and inventory shortage with full backorder. The impact of an inspection policy is investigated on the optimality of the solution under hybrid payment strategies for the deteriorating products. The validation and effectiveness of the proposed model and its solution method is assessed through several numerical examples. The outcomes suggest significant importance of the proposed inventory model and its solution method to the retail managers under real-world situations. The retail managers should consider inclusion of an inspection policy for mixed inventory sales as the policy potentially increases the net annual total profit.

A limitation of the proposed model is that it does not consider a few realistic assumptions. Therefore, future research should consider inclusion of these assumptions into the proposed inventory model. The presented model has been developed under two situations, viz. without shortage of products and full backordering. However, in reality, a situation may arise where customers may not pay for the backordered products when the stocked out items are available again. Therefore, future research can be directed considering partial backordering in the model. Another shortfall of the proposed model is that it considers the inventory deterioration right after their arrival. In reality, in some cases deterioration does not occur right after their arrival. Therefore, the proposed model can be extended for non-instantaneous deteriorating products such as fruits and vegetable. Future research may include another variant of the proposed model by inclusion of special sales or pricing policies into the inventory models.

Open Access This article is distributed under the terms of the Creative Commons Attribution 4.0 International License (http://creativecommons.org/licenses/by/4.0/), which permits unrestricted use, distribution, and reproduction in any medium, provided you give appropriate credit to the original author(s) and the source, provide a link to the Creative Commons license, and indicate if changes were made.

\section{Appendix A}

See Table 6. 
Table 6 List of notations

\begin{tabular}{|c|c|}
\hline \multicolumn{2}{|c|}{ Parameters and indices } \\
\hline$\lambda$ & Demand rate \\
\hline$\theta$ & Deterioration rate \\
\hline$C_{p}$ & Unit purchasing cost \\
\hline$C_{h}$ & Unit holding cost \\
\hline$C_{b}$ & Unit back-ordering cost \\
\hline$P$ & Unit selling price \\
\hline$A$ & Fixed ordering cost per order \\
\hline$d$ & Booking cost per inspection \\
\hline$D$ & Unit inspecting cost \\
\hline$i_{k}$ & Annual interest paid \\
\hline$i_{e}$ & Annual interest earned \\
\hline$n$ & Number of equally spaced prepayments \\
\hline$L$ & Length of prepayment \\
\hline$W$ & Predetermined threshold \\
\hline$M$ & Length of delayed payment \\
\hline$\beta$ & Percentage of purchasing cost that must be prepaid \\
\hline$T_{0}$ & Time interval in which $\alpha Q$ Units are depleted to zero \\
\hline$\underline{T_{w}}$ & Time interval in which $W$ units are depleted to zero $\left(T_{w}=W / \lambda\right)$ \\
\hline \multicolumn{2}{|c|}{ Decision variables } \\
\hline$T$ & Length of replenishment cycle \\
\hline$F$ & Fraction of demand that will be filled from inventory \\
\hline$Q$ & Order quantity \\
\hline$\tau$ & Inspection time \\
\hline$(*)$ & Indicates the optimal value \\
\hline \multicolumn{2}{|c|}{ Other variables (dependent variables) } \\
\hline$A T C_{i}$ & Annual total cost for case $i$ \\
\hline$A T P_{i}$ & Annual total profit for case $i$ \\
\hline$I E$ & Interest earned \\
\hline$I C$ & Interest charged \\
\hline
\end{tabular}

\section{Appendix B}

The first and second derivatives of $A T C_{1}(T)$ with reference to $T$ yields to:

$$
\frac{d A T C_{1}(T)}{d T}=\varphi_{1}-\frac{\varphi_{2}}{T^{2}}
$$

and

$$
\frac{\partial^{2} A T C_{1}(T)}{\partial T^{2}}=\frac{\varphi_{2}}{T^{3}}>0
$$


Since $\varphi_{2}$ is positive, the second derivative is positive for each value of $\varphi_{2}$. Therefore, $A T C_{1}(T)$ is proved to be convex. Thus, by setting the first derivative of $A T C_{1}(T)$ equal to 0 , global minimum is achieved. It is to be noted that the global minimum of $A_{T C}(T)$ is equivalent to the global maximum of $\operatorname{ATP}_{1}(T)$.

Here, let us find the value obtained from Eq. (27). As $\varphi_{1}$ and $\varphi_{2}$ are positive, $\frac{\varphi_{2}}{\varphi_{1}}$ is strictly positive, which means $T_{(1)}$ is positive.

\section{Appendix C}

As maximising $A T P_{1}(T, F)$ is equivalent to minimising $A T C_{1}(T, F)$, we prove that solution given by setting first derivative of $A T C_{1}(T)$ is a global minimum.

$$
A T C_{1}(T, F)=F^{2} T \varphi_{1}+\frac{\varphi_{2}}{T}+T\left(\frac{\varphi_{3}}{2}\right)-F T\left(\varphi_{3}\right)
$$

After rewriting the above function, we have:

$$
A T C_{1}(T, F)=\frac{\varphi_{2}}{T}+T\left(F^{2} \varphi_{1}+\left(\frac{\varphi_{3}}{2}\right)-F\left(\varphi_{3}\right)\right)
$$

For notational convenience, we define $\vartheta(F)=F^{2} \varphi_{1}-F \varphi_{3}+\frac{\varphi_{3}}{2}$ and we have:

$$
A T C_{1}(T, F)=\frac{\varphi_{2}}{T}+T \vartheta(F)
$$

The first and second derivatives of $A T C_{1}(T)$ with reference to $T$ yields to:

$$
\frac{d A T C_{1}(T, F)}{d T}=-\frac{\varphi_{2}}{T^{2}}+\vartheta(F)
$$

After setting above equation equal to 0 , we obtain:

$$
T^{*}(F)=\sqrt{\frac{\varphi_{2}}{\vartheta(F)}}
$$

$\vartheta(F)$ has no roots since $\Delta=b^{2}-4 a c=\varphi_{3}^{2}-2 \varphi_{1} \varphi_{3}=\varphi_{3}\left[-2 A\left(P \theta \lambda+C_{h} \lambda\right)\right]$ is negative, which means $\vartheta(F)$ obtains either positive or negative value. As $\vartheta(F=0)=\frac{\varphi_{3}}{2}>0, \vartheta(F)$ is positive for each value of $F$ in $[0,1]$. Thus, it is concluded that Eq. (C5) gives a unique optimal solution of $T^{*}(F)$ that minimises $A T C_{1}(T, F)$ for each value of $F$. Substituting $T^{*}(F)$ from equation (C5) into Eq. (C2) yields to:

$$
A T C_{1}(F, T(F))=2 \sqrt{\varphi_{2} \vartheta(F)}
$$

To obtain the global minimum of the function, we have taken the first and second derivatives of $A T C_{1}(T, T(F))$ with reference to $F$, which yields to:

$$
\frac{d A T C_{1}(F)}{d F}=\sqrt{\frac{\varphi_{2}}{\vartheta(F)}} * \vartheta^{\prime}(F)=\sqrt{\frac{\varphi_{2}}{F^{2} \varphi_{1}-F \varphi_{3}+\frac{\varphi_{3}}{2}}} *\left(2 F \varphi_{1}-\varphi_{3}\right)
$$




$$
\begin{aligned}
\frac{\partial^{2} A T C_{1}(F)}{\partial F^{2}} & =\frac{\sqrt{\varphi_{2}}}{2}\left[\frac{2 \vartheta^{\prime \prime}(F) \times \vartheta(F)-\vartheta^{\prime}(F)^{2}}{\sqrt{\vartheta(F)^{3}}}\right] \\
& =\frac{\sqrt{\varphi_{2}}}{2}\left[\frac{2\left(2 \varphi_{1}\right)\left(F^{2} \varphi_{1}-F \varphi_{3}+\frac{\varphi_{3}}{2}\right)-\left(2 F \varphi_{1}-\varphi_{3}\right)^{2}}{\sqrt{\vartheta(F)^{3}}}\right] \\
& =\frac{\sqrt{\varphi_{2}}}{2}\left[\frac{\varphi_{3}\left(2 \varphi_{1}-\varphi_{3}\right)}{\sqrt{\vartheta(F)^{3}}}\right] \\
& =\frac{\varphi_{3} \sqrt{\varphi_{2}}}{2 \sqrt{\vartheta(F)^{3}}}\left(P \theta \lambda+C_{h} \lambda\right)>0
\end{aligned}
$$

Thus, $A T C_{1}(T, T(F))$ is convex. Moreover:

$$
\begin{gathered}
\left.\frac{d A T C_{1}(F)}{d F}\right|_{F=0}=-\sqrt{2 \varphi_{2} \varphi_{3}}<0 \\
\left.\frac{d A T C_{1}(F)}{d F}\right|_{F=1}=\sqrt{2 \varphi_{2}\left(2 \varphi_{1}-\varphi_{3}\right)}=\sqrt{2 A\left(P \theta \lambda+C_{h} \lambda\right)}>0
\end{gathered}
$$

We conclude from Eqs. (C7), (C8) and (C9) that the obtained solution has a unique optimal value. Here, let us find the values obtained from Eqs. (42) and (43). Earlier it was mentioned that $\vartheta(F)$ is strictly positive, which means $\frac{\varphi_{2}}{\vartheta(F)}$ is strictly positive and the value of $T^{*}(F)$ is positive as well. It can be proved that the value of $F_{(1)}$ is also positive as $\varphi_{1}$ and $\varphi_{3}$ are positive. It is important that $F_{(1)}$ should take a value on the interval [0,1]. Therefore, after simplifying Eq. (42), we obtain $F_{(1)}=\frac{\varphi_{3}}{2 \varphi_{1}}=\frac{C_{b} \lambda}{P \theta \lambda+\left(C_{h}+C_{b}\right) \lambda}$ for an interval $[0,1]$ since $C_{b} \lambda \leq P \theta \lambda+C_{h} \lambda+C_{b} \lambda$.

\section{Appendix D}

As illustrated in Fig. 10, since the inventory level at $\tau$ is equal to $I(\tau)=(Q-\lambda \tau) \times e^{-\theta \tau}$, the inventory reaches to 0 at time

$$
t_{0}=\tau+\left(\frac{Q}{\lambda}-\tau\right) e^{-\theta \tau}
$$

By differentiating $t_{0}$ with respect to $\tau, \tau^{*}$ is obtained which minimises the value of $t=t_{0}$. When $T$ is less than the minimum value $t_{0}$, extra products are remained at the end of the cycle.

$$
\frac{d t_{0}}{d \tau}=1-\theta\left(\frac{Q}{\lambda}-\tau\right) e^{-\theta \tau}-e^{-\theta \tau}
$$


and

$$
\frac{d^{2} t_{0}}{d \tau^{2}}=\theta^{2}\left(\frac{Q}{\lambda}-\tau\right) e^{-\theta \tau}+2 e^{-\theta \tau} \geq 0
$$

So, $t_{0}$ is strictly convex function in $\tau$ and, therefore, has a global minimum in the interval $[0, T]$. By substituting $e^{x} \approx 1+x+\frac{x^{2}}{2}$ for the exponential term:

$$
\begin{array}{r}
\frac{d t_{0}}{d \tau}=1-\left(\frac{Q \theta}{\lambda}+\theta \tau-1\right)\left(1-\theta \tau+\frac{\theta^{2} \tau^{2}}{2}\right)=0 \\
\rightarrow \frac{\theta}{2 \lambda}\left[\left(\lambda \theta^{2}\right) \tau^{3}-\left(Q \theta^{2}+3 \lambda \theta\right) \tau^{2}+(2 Q \theta+4 \lambda) \tau-2 Q\right]=0 \\
{\left[\left(\lambda \theta^{2}\right) \tau^{* 3}-\left(Q \theta^{2}+3 \lambda \theta\right) \tau^{* 2}+(2 Q \theta+4 \lambda) \tau^{*}-2 Q\right]=0}
\end{array}
$$

\section{References}

Aggarwal, S. P., \& Jaggi, C. K. (1995). Ordering policies of deteriorating items under permissible delay in payments. Journal of the Operational Research Society, 46(5), 658-662.

Bakker, M., Riezebos, J., \& Teunter, R. H. (2012). Review of inventory systems with deterioration since 2001. European Journal of Operational Research, 221(2), 275-284.

Chang, H.-C., Ho, C.-H., Ouyang, L.-Y., \& Su, C.-H. (2009). The optimal pricing and ordering policy for an integrated inventory model when trade credit linked to order quantity. Applied Mathematical Modelling, 33(7), 2978-2991.

Chen, L.-H., \& Kang, F.-S. (2010). Integrated inventory models considering the two-level trade credit policy and a price-negotiation scheme. European Journal of Operational Research, 205(1), 47-58.

Chen, S.-C., Cárdenas-Barrón, L. E., \& Teng, J.-T. (2014). Retailer's economic order quantity when the supplier offers conditionally permissible delay in payments link to order quantity. International Journal of Production Economics, 155, 284-291.

Chen, S.-C., \& Teng, J.-T. (2015). Inventory and credit decisions for time-varying deteriorating items with up-stream and down-stream trade credit financing by discounted cash flow analysis. European Journal of Operational Research, 243(2), 566-575.

Chung, C.-J., Wee, H.-M., \& Chen, Y.-L. (2013). Retailer's replenishment policy for deteriorating item in response to future cost increase and incentive-dependent sale. Mathematical and Computer Modelling, $57(3-4), 536-550$.

Chung, K.-J. (2013). The EOQ model with defective items and partially permissible delay in payments linked to order quantity derived analytically in the supply chain management. Applied Mathematical Modelling, 37(4), 2317-2326.

Chung, K.-J., \& Liao, J.-J. (2009). The optimal ordering policy of the EOQ model under trade credit depending on the ordering quantity from the DCF approach. European Journal of Operational Research, 196(2), 563-568.

Covert, R. P., \& Philip, G. C. (1973). An EOQ model for items with Weibull distribution deterioration. AIIE Transactions, 5(4), 323-326.

Das, D., Roy, A., \& Kar, S. (2015). A multi-warehouse partial backlogging inventory model for deteriorating items under inflation when a delay in payment is permissible. Annals of Operations Research, 226(1), 133-162.

Dobson, G., Pinker, E. J., \& Yildiz, O. (2017). An EOQ model for perishable goods with age-dependent demand rate. European Journal of Operational Research, 257(1), 84-88.

Ghare, P. M., \& Schrader, G. F. (1963). A model for exponentially decaying inventories. Journal of Industrial Engineering, 14, 238-243.

Ghoreishi, M., Weber, G.-W., \& Mirzazadeh, A. (2015). An inventory model for non-instantaneous deteriorating items with partial backlogging, permissible delay in payments, inflation- and selling pricedependent demand and customer returns. Annals of Operations Research, 226(1), 221-238.

Goyal, S. K. (1985). Economic order quantity under conditions of permissible delay in payments. Journal of the Operational Research Society, 36(4), 335-338. 
Goyal, S. K., \& Giri, B. C. (2001). Recent trends in modeling of deteriorating inventory. European Journal of Operational Research, 134(1), 1-16.

Guria, A., Das, B., Mondal, S., \& Maiti, M. (2013). Inventory policy for an item with inflation induced purchasing price, selling price and demand with immediate part payment. Applied Mathematical Modelling, 37(1-2), 240-257.

Huang, Y.-F. (2007). Economic order quantity under conditionally permissible delay in payments. European Journal of Operational Research, 176(2), 911-924.

Jaggi, C. K., Gupta, M., Kausar, A., \& Tiwari, S. (2019). Inventory and credit decisions for deteriorating items with displayed stock dependent demand in two-echelon supply chain using Stackelberg and Nash equilibrium solution. Annals of Operations Research, 274(1-2), 309-329.

Jaggi, C. K., Tiwari, S., \& Goel, S. K. (2017). Credit financing in economic ordering policies for noninstantaneous deteriorating items with price dependent demand and two storage facilities. Annals of Operations Research, 248(1-2), 253-280.

Jamal, A. M. M., Sarker, B. R., \& Wang, S. (1997). An ordering policy for deteriorating items with allowable shortage and permissible delay in payment. Journal of the Operational Research Society, 48(8), $826-833$.

Kawale, S., \& Sanas, Y. (2017). A review on inventory models under trade credit. International Journal of Mathematics in Operational Research, 11(4), 520-543.

Kaya, O., \& Polat, A. L. (2017). Coordinated pricing and inventory decisions for perishable products. $O R$ Spectrum, 39(2), 589-606.

Khan, M., Jaber, M. Y., \& Bonney, M. (2011a). An economic order quantity (EOQ) for items with imperfect quality and inspection errors. International Journal of Production Economics, 133(1), 113-118.

Khan, M., Jaber, M. Y., Guiffrida, A. L., \& Zolfaghari, S. (2011b). A review of the extensions of a modified EOQ model for imperfect quality items. International Journal of Production Economics, 132(1), 1-12.

Khouja, M., \& Mehrez, A. (1996). Optimal inventory policy under different supplier credit policies. Journal of Manufacturing Systems, 15(5), 334-339.

Kreng, V. B., \& Tan, S.-J. (2011). Optimal replenishment decision in an EPQ model with defective items under supply chain trade credit policy. Expert Systems with Applications, 38(8), 9888-9899.

Lashgari, M., Taleizadeh, A. A., \& Ahmadi, A. (2016). Partial up-stream advanced payment and partial down-stream delayed payment in a three-level supply chain. Annals of Operations Research, 238(1-2), 329-354.

Lashgari, M., Taleizadeh, A. A., \& Sadjadi, S. J. (2018). Ordering policies for non-instantaneous deteriorating items under hybrid partial prepayment, partial trade credit and partial backordering. Journal of the Operational Research Society, 69(8), 1167-1196.

Lee, C. H., \& Rhee, B.-D. (2011). Trade credit for supply chain coordination. European Journal of Operational Research, 214(1), 136-146.

Mahata, G. C. (2012). An EPQ-based inventory model for exponentially deteriorating items under retailer partial trade credit policy in supply chain. Expert Systems with Applications, 39(3), 3537-3550.

Mahata, P., Mahata, G. C., \& De, S. K. (2018). An economic order quantity model under two-level partial trade credit for time varying deteriorating items. International Journal of Systems Science: Operations andLogistics, pp. 1-17.

Maihami, R., Karimi, B., \& Ghomi, S. M. T. F. (2017). Effect of two-echelon trade credit on pricing-inventory policy of non-instantaneous deteriorating products with probabilistic demand and deterioration functions. Annals of Operations Research, 257(1-2), 237-273.

Maiti, A. K., Maiti, M. K., \& Maiti, M. (2009). Inventory model with stochastic lead-time and price dependent demand incorporating advance payment. Applied Mathematical Modelling, 33(5), 2433-2443.

Min, J., Zhou, Y.-W., \& Zhao, J. (2010). An inventory model for deteriorating items under stock-dependent demand and two-level trade credit. Applied Mathematical Modelling, 34(11), 3273-3285.

Mishra, U., Cárdenas-Barrón, L. E., Tiwari, S., Shaikh, A. A., \& Treviño-Garza, G. (2017). An inventory model under price and stock dependent demand for controllable deterioration rate with shortages and preservation technology investment. Annals of Operations Research, 254(1-2), 165-190.

Musa, A., \& Sani, B. (2012). Inventory ordering policies of delayed deteriorating items under permissible delay in payments. International Journal of Production Economics, 136(1), 75-83.

Olsson, F. (2014). Analysis of inventory policies for perishable items with fixed leadtimes and lifetimes. Annals of Operations Research, 217(1), 399-423.

Ouyang, L.-Y., \& Chang, C.-T. (2013). Optimal production lot with imperfect production process under permissible delay in payments and complete backlogging. International Journal of Production Economics, 144(2), 610-617. 
Ouyang, L.-Y., Teng, J.-T., Goyal, S. K., \& Yang, C.-T. (2009). An economic order quantity model for deteriorating items with partially permissible delay in payments linked to order quantity. European Journal of Operational Research, 194(2), 418-431.

Pentico, D. W., \& Drake, M. J. (2011). A survey of deterministic models for the EOQ and EPQ with partial backordering. European Journal of Operational Research, 214(2), 179-198.

Pentico, D. W., Drake, M. J., \& Toews, C. (2009). The deterministic EPQ with partial backordering: A new approach. Omega, 37(3), 624-636.

Prasad, K., \& Mukherjee, B. (2016). Optimal inventory model under stock and time dependent demand for time varying deterioration rate with shortages. Annals of Operations Research, 243(1-2), 323-334.

Salameh, M. K., \& Jaber, M. Y. (2000). Economic production quantity model for items with imperfect quality. International Journal of Production Economics, 64(1-3), 59-64.

Sarkar, B., Saren, S., \& Cárdenas-Barrón, L. E. (2015). An inventory model with trade-credit policy and variable deterioration for fixed lifetime products. Annals of Operations Research, 229(1), 677-702.

Sarkar, B., \& Sarkar, S. (2013). An improved inventory model with partial backlogging, time varying deterioration and stock-dependent demand. Economic Modelling, 30, 924-932.

Seifert, D., Seifert, R. W., \& Protopappa-Sieke, M. (2013). A review of trade credit literature: Opportunities for research in operations. European Journal of Operational Research, 231(2), 245-256.

Skouri, K., Konstantaras, I., Papachristos, S., \& Teng, J.-T. (2011). Supply chain models for deteriorating products with ramp type demand rate under permissible delay in payments. Expert Systems with Applications, 38(12), 14861-14869.

Soni, H. N., \& Patel, K. A. (2012). Optimal strategy for an integrated inventory system involving variable production and defective items under retailer partial trade credit policy. Decision Support Systems, 54(1), 235-247.

Tai, A. H., Xie, Y., \& Ching, W.-K. (2016). Inspection policy for inventory system with deteriorating products. International Journal of Production Economics, 173, 22-29.

Taleizadeh, A. A. (2014a). An economic order quantity model for deteriorating item in a purchasing system with multiple prepayments. Applied Mathematical Modelling, 38(23), 5357-5366.

Taleizadeh, A. A. (2014b). An EOQ model with partial backordering and advance payments for an evaporating item. International Journal of Production Economics, 155, 185-193.

Taleizadeh, A. A., \& Nematollahi, M. (2014). An inventory control problem for deteriorating items with back-ordering and financial considerations. Applied Mathematical Modelling, 38(1), 93-109.

Taleizadeh, A. A., \& Noori-Daryan, M. (2015). Pricing, manufacturing and inventory policies for raw material in a three-level supply chain. International Journal of Systems Science, 47(4), 919-931.

Taleizadeh, A. A., Pentico, D. W., Jabalameli, M. S., \& Aryanezhad, M. (2013a). An economic order quantity model with multiple partial prepayments and partial backordering. Mathematical and Computer Modelling, 57(3-4), 311-323.

Taleizadeh, A. A., Pentico, D. W., Jabalameli, M. S., \& Aryanezhad, M. (2013b). An EOQ model with partial delayed payment and partial backordering. Omega, 41(2), 354-368.

Taleizadeh, A. A., Tavakoli, S., \& San-José, L. A. (2018). A lot sizing model with advance payment and planned backordering. Annals of Operations Research. https://doi.org/10.1007/s10479-018-2753-y. (in Press).

Taleizadeh, A. A., Wee, H. M., \& Jolai, F. (2013c). Revisiting fuzzy rough economic order quantity model for deteriorating items considering quantity discount and prepayment. Mathematical and Computer Modelling, 57(5-6), 1466-1479.

Tat, R., Taleizadeh, A. A., \& Esmaeili, M. (2015). Developing EOQ model with non-instantaneous deteriorating items in vendor-managed inventory (VMI) system. International Journal of Systems Science, 46(7), 1257-1268.

Tavakoli, S., \& Taleizadeh, A. A. (2017). An EOQ model for decaying item with full advanced payment and conditional discount. Annals of Operations Research, 259(1-2), 415-436.

Teng, J.-T. (2002). On the economic order quantity under conditions of permissible delay in payments. Journal of the Operational Research Society, 53(8), 915-918.

Teng, J.-T. (2009). Optimal ordering policies for a retailer who offers distinct trade credits to its good and bad credit customers. International Journal of Production Economics, 119(2), 415-423.

Teng, J.-T., Yang, H.-L., \& Chern, M.-S. (2013). An inventory model for increasing demand under two levels of trade credit linked to order quantity. Applied Mathematical Modelling, 37(14-15), 7624-7632.

Thangam, A. (2012). Optimal price discounting and lot-sizing policies for perishable items in a supply chain under advance payment scheme and two-echelon trade credits. International Journal of Production Economics, 139(2), 459-472. 
Ting, P.-S. (2015). Comments on the EOQ model for deteriorating items with conditional trade credit linked to order quantity in the supply chain management. European Journal of Operational Research, 246(1), $108-118$.

Tiwari, S., Jaggi, C. K., Bhunia, A. K., Shaikh, A. A., \& Goh, M. (2017). Two-warehouse inventory model for non-instantaneous deteriorating items with stock-dependent demand and inflation using particle swarm optimization. Annals of Operations Research, 254(1-2), 401-423.

Vandana, \& Sharma, B. K. (2016). An EOQ model for retailers partial permissible delay in payment linked to order quantity with shortages. Mathematics and Computers in Simulation, 125, 99-112.

Wu, J., Ouyang, L.-Y., Cárdenas-Barrón, L. E., \& Goyal, S. K. (2014). Optimal credit period and lot size for deteriorating items with expiration dates under two-level trade credit financing. European Journal of Operational Research, 237(3), 898-908.

Zhang, A. X. (1996). Optimal advance payment scheme involving fixed per-payment costs. Omega, 24(5), $577-582$.

Zhang, Q., Tsao, Y.-C., \& Chen, T.-H. (2014). Economic order quantity under advance payment. Applied Mathematical Modelling, 38(24), 5910-5921.

Zia, N. P., \& Taleizadeh, A. A. (2015). A lot-sizing model with backordering under hybrid linked-to-order multiple advance payments and delayed payment. Transportation Research Part E: Logistics and Transportation Review, 82, 19-37.

Publisher's Note Springer Nature remains neutral with regard to jurisdictional claims in published maps and institutional affiliations.

\section{Affiliations}

\section{Ata Allah Taleizadeh ${ }^{1} \cdot$ Sara Tavassoli $^{1} \cdot$ Arijit Bhattacharya $^{2}$}

Ata Allah Taleizadeh

taleizadeh@ut.ac.ir

Sara Tavassoli

tavassoli.st@gmail.com

1 School of Industrial Engineering, College of Engineering, University of Tehran, Tehran, Iran

2 Norwich Business School, University of East Anglia, Norwich Research Park, Norwich NR4 7TJ, UK 